Review

\title{
Recent developments in the use of single-atom catalysts for water splitting
}

\author{
Yao Wang a,b, Xun Huang b,*, Zidong Wei ${ }^{b}$ \\ a Institute of New-Energy and Low-Carbon Technology, Sichuan University, Chengdu 610065, Sichuan, China \\ b Chongqing Key Laboratory of Chemical Process for Clean Energy and Resource Utilization, College of Chemistry and Chemical Engineering, Chongqing \\ University, Chongqing 400044, China
}

\section{A R T I C L E I N F O}

\section{Article history:}

Received 23 September 2020

Accepted 24 October 2020

Available online 5 April 2021

\section{Keywords:}

Single-atom catalyst

Electrochemical water splitting

Inherent element property

Coordination environment

Geometric structure

\begin{abstract}
A B S T R A C T
Electrochemical water splitting is regarded as the most promising approach to produce hydrogen. However, the sluggish electrochemical reactions occurring at the anode and cathode, namely, the oxygen evolution reaction (OER) and the hydrogen evolution reaction (HER), respectively, consume a tremendous amount of energy, seriously hampering its wide application. Recently, single-atom catalysts (SACs) have been proposed to effectively enhance the kinetics of these two reactions. In this minireview, we focus on the recent progress in SACs for OER and HER applications. Three classes of SACs have been reviewed, i.e., alloy-based SACs, carbon-based SACs and SACs supported on other compounds. Different factors affecting the activities of SACs are also highlighted, including the inherent element property, the coordination environment, the geometric structure and the loading amount of metal atoms. Finally, we summarize the current problems and directions for future development in SACs.
\end{abstract}

(C) 2021, Dalian Institute of Chemical Physics, Chinese Academy of Sciences. Published by Elsevier B.V. All rights reserved.

\section{Introduction}

Over the past century, hydrogen has been exploited worldwide and utilized as an industrial gas in many applications. To alleviate human energy crisis and environment issues, hydrogen has been proposed as an energy carrier to replace fossil fuels, since it can provide up to almost 3 times the specific energy obtained using gasoline, without any carbon emission. Many strategies have been suggested for hydrogen production. Currently, hydrogen is mostly produced from fossil sources via thermal reaction. However, not only does this thermal reaction lead to the release of greenhouse gases, but also produces hydrogen along with carbon monoxide, which is believed to be harmful for hydrogen application in fuel cells. Electrochemical water splitting, which can produce clean hydrogen without any carbon monoxide impurities and carbon emissions, is the focus of interest in recent research [1-3]. When coupled with intermittent renewable energy sources (solar, wind etc.), which may not be sustainable in the long term, electrochemical water splitting has several advantages. On the one hand, it can provide a continuous hydrogen energy supply by utilizing the electricity converted from intermittent renewable energy sources; on the other hand, it can easily solve the problem of storage of the surplus renewable electricity. Nevertheless, electrochemical water splitting has a relatively small market share in the production of hydrogen. A major factor is the high energy consumption. Electrochemical water splitting involves two half-cell reactions, i.e., hydrogen evolution reaction (HER) and

\footnotetext{
* Corresponding author. Tel/Fax: +86-23-65678931; E-mail: huangxun@cqu.edu.cn

This work was supported by the National Natural Science Foundation of China (21761162015, 91834301, 21908148), Sichuan Science and Technology Program (2020YJ0088), and the Fundamental Research Funds for the Central Universities.

DOI: 10.1016/S1872-2067(20)63619-1 | http://www.sciencedirect.com/journal/chinese-journal-of-catalysis | Chin. J. Catal., Vol. 42, No. 8, August 2021
} 
oxygen evolution reaction (OER). To decrease the high energy consumption, it is necessary to develop effective catalysts to promote the kinetics of these two reactions [4-12]. Precious metal-based catalysts ( $\mathrm{Pt}, \mathrm{IrO}_{2}, \mathrm{RuO}_{2}$ etc.) have been considered to be the most efficient catalysts to facilitate HER and OER; however, the high cost and scarcity of these precious metal-based catalysts deter their use in practical applications [13-20]. Clearly, it is desirable to develop catalysts with trace amounts of precious metal or without any precious metal.

Single-atom catalysts (SACs), in which the metal atoms are isolated on supports, have emerged as a new frontier [21-35]. Compared to catalysts with nanoparticles and metal clusters, the SACs feature significantly different structures and characteristics, which give them superior activity, selectivity, and durability for many catalytic reactions. Firstly, the single metal atoms are usually the unsaturated coordination atoms, which are generally regarded as the active centers for many reactions. Secondly, the strong metal-support interactions (SMSI) in SACs may be enhanced, leading to increased electron transfer between the metal atoms and the support, which in turn modulates the electronic structure of metal atoms. Thirdly, owing to the quantum size effect, the metal atoms in SACs always exhibit a unique HOMO-LOMO gap and a discrete energy level distribution, which gives them a distinct energy level structure. Most importantly, it is possible to achieve a theoretical efficiency of $100 \%$ in catalytic reactions, due to the atomic dispersion configuration in SACs. Due to these advantages, SACs are considered to have bright prospects for applications in electrochemical water splitting. On the one hand, the single-dispersed active sites in SACs can significantly promote the utilization of the metal atoms, which would mean that the amount of the precious metal needed for the synthesis of SACs would be markedly reduced, leading to a decrease in cost. Indeed, several SAC catalysts based on precious metals such as $\mathrm{Pt}, \mathrm{Ru}$ and Ir have been intensively investigated [36-43]. These precious metal-based SACs possess an enhanced mass activity compared to the corresponding nanoparticle catalysts. On the other hand, non-precious metal-based SACs have also been extensively used due to their considerably lower cost [44-50]. Owing to the SMSI, the non-precious metal active sites can be modulated, achieving activities comparable to that of catalysts based on precious metals. In addition, the existence of SMSI ensures a robust durability for SACs, making it possible to use non-precious-metal-based catalysts in acid medium. Moreover, the unique structure of single-dispersed active sites in SACs could provide a platform for clearly recognizing the actual intrinsic properties of the active sites and their catalytic mechanism on the triple phase boundary. Therefore, by virtue of the advanced experiment design and detailed theoretical calculations, much effort has been devoted to design and develop high-performance SACs for both HER and OER [51-56]. Several breakthroughs have been achieved lately, making it necessary to summarize the state-of-the-art advances in the field of SACs.

Recently, some excellent reviews have summarized the utilization of SACs for water splitting, in which the synthesis, strategies and applications of SACs are discussed [57-63]. In order to avoid repetition, this minireview focuses on the factors affecting the HER and OER performance of SACs. Also, the current challenges and future perspectives for the development of SACs for water splitting are highlighted here.

\section{Basic mechanism for water splitting reactions}

To design SACs with better performance, it is important to understand the basic mechanism of the reactions occurring on the electrode surfaces. Most electrochemical reactions consist of multiple elementary steps. Even for the HER, which is the simplest electrocatalytic reaction, Volmer-Heyrovsky and Volmer-Tafel mechanisms are proposed to explain how this reaction occurs in both acidic and basic solutions. The OER, which involves four electrons, are more complex than HER. In this section, the basic mechanisms for both HER and OER are summarized.

\subsection{HER}

As mentioned above, two mechanisms, Volmer-Heyrovsky and Volmer-Tafel, have gained acceptance for HER, in general. The first step in both these mechanisms is the Volmer reaction, in which $\mathrm{H}^{+}$(in acidic medium) or $\mathrm{H}_{2} \mathrm{O}$ molecule (in alkaline medium) couples with an electron to form an adsorbed hydrogen atom on the electron surface via a discharge process (Eq. (1) in acidic medium and Eq. (2) in alkaline medium). Subsequently, depending on the amount of hydrogen adsorbed on the electrode surface, $\mathrm{H}_{\mathrm{ads}}$, the reduction of $\mathrm{H}_{\mathrm{ads}}$ to generate $\mathrm{H}_{2}$ follows either the Heyrovsky reaction, or the Tafel reaction. When $\mathrm{H}_{\text {ads }}$ is high, the adsorbed hydrogen atoms combine with each other directly. This recombination reaction is known as the Tafel reaction (Eq. (3) in both acidic and alkaline media). In the case of low surface coverage, $\mathrm{H}_{\text {ads }}$ reacts with another $\mathrm{H}^{+}$(in acidic medium) or $\mathrm{H}_{2} \mathrm{O}$ molecule (in alkaline medium), accompanied by a second electron transfer, to release $\mathrm{H}_{2}$. This step, involving electron transfer, is called the electrochemical desorption reaction, or the Heyrovsky reaction, and it is represented by Eq. (4) in acidic medium and Eq. (5) in alkaline medium.

Volmer reaction:

$$
\begin{aligned}
& \mathrm{M}+\mathrm{H}^{+}(\mathrm{aq})+\mathrm{e}^{-} \rightarrow \mathrm{M}-\mathrm{H}_{\mathrm{ads}} \\
& \mathrm{M}+\mathrm{H}_{2} \mathrm{O}(\mathrm{aq})+\mathrm{e}^{-} \rightarrow \mathrm{M}-\mathrm{H}_{\mathrm{ads}}+\mathrm{OH}^{-}
\end{aligned}
$$

where $\mathrm{M}$ represents the catalyst surface.

Tafel reaction:

$$
\begin{aligned}
& \text { M-Hads }+\mathrm{M}-\mathrm{H}_{\mathrm{ads}} \rightarrow \mathrm{H}_{2} \\
& \text { Heyrovsky reaction: } \\
& \text { M- } \mathrm{H}_{\mathrm{ads}}+\mathrm{H}^{+}(\mathrm{aq})+\mathrm{e}^{-} \rightarrow \mathrm{M}+\mathrm{H}_{2} \\
& \mathrm{M}-\mathrm{H}_{\mathrm{ads}}+\mathrm{H}_{2} \mathrm{O}(\mathrm{aq})+\mathrm{e}^{-} \rightarrow \mathrm{M}+\mathrm{H}_{2}+\mathrm{OH}^{-}
\end{aligned}
$$

For a specific catalyst, the Tafel slope, which depends on the mechanism of HER occurring at the surface of the catalyst, can be used as an indicator. The theoretical values for the Tafel slope, as estimated from Butler-Volmer kinetics, are 118, 40

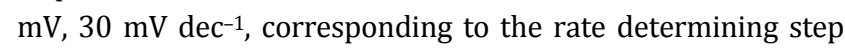
being the Volmer reaction, the Heyrovsky reaction, or the Tafel reaction, respectively. Further, if the Tafel slope measured at a

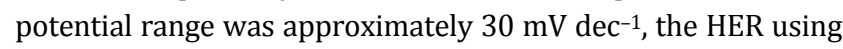
that catalyst was likely to follow the Volmer-Tafel mechanism, 
with the Tafel reaction as the rate determining step [64].

Although different HER mechanisms are possible, the HER occurring on the surface of catalysts basically consists of hydrogen adsorption and hydrogen desorption. According to the Sabatier principle, if $\mathrm{H}_{\text {ads }}$ is strongly adsorbed on the surface of catalysts, the desorption of hydrogen would be very difficult, and vice versa, which would inhibit the hydrogen evolution process. A desirable HER catalyst must show moderate ability for hydrogen adsorption, i.e., the bonding energy of $\mathrm{M}-\mathrm{H}_{\text {ads }}$ should be neither too strong nor too weak. Indeed, experimental and theoretical studies indicate that the hydrogen adsorption free energy $\left(\Delta G_{H^{*}}\right)$ of the catalysts plays a crucial role in their HER activities, as shown in Fig. 1(a) $[64,65]$. When $\Delta G_{\mathrm{H}^{*}}$ $\approx 0 \mathrm{eV}$, where the $\mathrm{M}-\mathrm{H}_{\text {ads }}$ bonding energy is the most moderate, the catalysts are found to exhibit the highest HER activity. In other words, $\Delta \mathrm{G}_{\mathrm{H}^{*}}$ can be regarded as a descriptor for the HER activity of catalysts. However, many other factors, such as conductivity, interface effect, and crystal structure may also affect the activities of the catalysts. Therefore, it is necessary to analyze the mechanism of HER for each catalyst.

\section{2. $O E R$}

Compared to HER, OER is more complex since it consists of four elementary steps. In acid medium, $\mathrm{O}_{2}$ molecule originates from the $\mathrm{H}_{2} \mathrm{O}$ molecule, while $\mathrm{OH}^{-}$is assumed to be the precursor for $\mathrm{O}_{2}$ in alkaline medium. The OER mechanisms in different media are discussed in this section.

In acid medium, $\mathrm{H}_{2} \mathrm{O}$ molecule would be adsorbed on the catalyst surface. After one electron transfer, $\mathrm{OH}_{\text {ads }}$ would form on the surface of the catalysts, as shown in Eq. (6). The adsorbed $\mathrm{OH}_{\text {ads }}$ may couple with each other to generate $\mathrm{O}_{\text {ads }}$ on the surface of the catalysts, while releasing $\mathrm{H}_{2} \mathrm{O}$ (Eq. (7)) or lose the second electron to form $\mathrm{O}_{\text {ads }}$ directly (Eq. (8)). Two $\mathrm{O}_{\text {ads }}$ intermediates on the catalyst surface may combine with each other to directly release the $\mathrm{O}_{2}$ molecule, as shown in Eq. (9). Yet another mechanism involving $\mathrm{O}_{\text {ads }}$ intermediates has also been proposed. It is speculated that $\mathrm{O}_{\text {ads }}$ intermediates on the surface of catalyst may react with another $\mathrm{H}_{2} \mathrm{O}$ molecule to form $\mathrm{OOH}_{\mathrm{ads}}$, accompanied by a third electron transfer (Eq. (10)). The adsorbed $\mathrm{OOH}$ would then decompose to produce
$\mathrm{O}_{2 \cdot}$ (Eq. (11))

$$
\begin{aligned}
\mathrm{M}+\mathrm{H}_{2} \mathrm{O} & \rightarrow \mathrm{M}-\mathrm{OH}_{\mathrm{ads}}+\mathrm{H}^{+}+\mathrm{e}^{-} \\
\mathrm{M}-\mathrm{OH}_{\text {ads }}+\mathrm{M}-\mathrm{OH}_{\text {ads }} & \rightarrow \mathrm{M}-\mathrm{O}_{\text {ads }}+\mathrm{M}+\mathrm{H}_{2} \mathrm{O} \\
\text { or } \mathrm{M}-\mathrm{OH}_{\mathrm{ads}} & \rightarrow \mathrm{M}-\mathrm{O}_{\text {ads }}+\mathrm{H}^{+}+\mathrm{e}^{-} \\
\mathrm{M}-\mathrm{O}_{\text {ads }}+\mathrm{M}-\mathrm{O}_{\text {ads }} & \rightarrow 2 \mathrm{M}+\mathrm{O}_{2} \\
\text { or } \mathrm{M}-\mathrm{O}_{\mathrm{ads}}+\mathrm{H}_{2} \mathrm{O} & \rightarrow \mathrm{M}-\mathrm{OOH}_{\mathrm{ads}}+\mathrm{H}^{+}+\mathrm{e}^{-} \\
\mathrm{M}-\mathrm{OOH}_{\text {ads }} & \rightarrow \mathrm{M}+\mathrm{O}_{2}+\mathrm{H}^{+}+\mathrm{e}^{-}
\end{aligned}
$$

In alkaline medium, the elementary steps are similar to those observed in acid medium. As shown in Eq. (12), the $\mathrm{OH}^{-}$ ion in alkaline medium takes the place of the $\mathrm{H}_{2} \mathrm{O}$ molecule in acid medium, to be first adsorbed on the catalyst surface. It is noted that $\mathrm{OH}_{\text {ads }}$ can directly react with the aqueous $\mathrm{OH}^{-}$to form $\mathrm{O}_{\text {ads }}$ on the catalyst surface (Eq. 13). Thereafter, two different pathways to release $\mathrm{O}_{2}$ exist in alkaline medium and are represented by Eq (14-16).

$$
\begin{aligned}
\mathrm{M}+\mathrm{OH}^{-} & \rightarrow \mathrm{M}-\mathrm{OH}_{\mathrm{ads}}+\mathrm{e}^{-} \\
\mathrm{M}-\mathrm{OH}_{\mathrm{ads}}+\mathrm{OH}^{-} & \rightarrow \mathrm{M}-\mathrm{O}_{\mathrm{ads}}+\mathrm{H}_{2} \mathrm{O}+\mathrm{e}^{-} \\
\mathrm{M}-\mathrm{O}_{\mathrm{ads}}+\mathrm{M}-\mathrm{O}_{\mathrm{ads}} & \rightarrow 2 \mathrm{M}+\mathrm{O}_{2} \\
\text { or } \mathrm{M}-\mathrm{O}_{\mathrm{ads}}+\mathrm{OH}^{-} & \rightarrow \mathrm{M}-\mathrm{OOH}_{\mathrm{ads}}+\mathrm{e}^{-} \\
\mathrm{M}-\mathrm{OOH}_{\mathrm{ads}}+\mathrm{OH}^{-} & \rightarrow \mathrm{M}+\mathrm{O}_{2}+\mathrm{H}_{2} \mathrm{O}+\mathrm{e}^{-}
\end{aligned}
$$

In both acid and alkaline media, the combination of $\mathrm{O}_{\text {ads }}$ intermediates to produce $\mathrm{O}_{2}$ is not very facile, owing to a large energy barrier [66]. Thus, the complete OER process can be represented as a sequence of four elementary steps, i.e., the OER follows the steps represented by Eq. (6) $\rightarrow$ Eq. (7 or 8) $\rightarrow$ Eq. $(10) \rightarrow$ Eq. (11) in acid medium, and Eq. (12) $\rightarrow$ Eq. (13) $\rightarrow$ Eq. (15) $\rightarrow$ Eq. (16) in alkaline medium. The overpotential for the OER is closely associated with the energetics of adsorption of the intermediates $\left(\mathrm{O}_{\mathrm{ads}}, \mathrm{OH}_{\mathrm{ads}}\right.$, and $\left.\mathrm{OOH}_{\mathrm{ads}}\right)$. The adsorption free energy of $\mathrm{OOH}_{\text {ads }}$ is known to be linearly related with that of $\mathrm{OH}_{\text {ads. }}$ The difference in the adsorption free energies of $\mathrm{O}$ and $\mathrm{OH}$, i.e., $\left(\Delta G_{0^{*}}-\Delta \mathrm{OH}^{*}\right)$, is considered to be a descriptor for the catalytic activity for OER. Thus, a volcano relationship between overpotential and $\left(\Delta G_{0^{*}}-\Delta_{\mathrm{OH}^{*}}\right)$ is proposed, as shown in Fig. 1(b) [67]. $\mathrm{IrO}_{2}$ and $\mathrm{RuO}_{2}$, which lie near the top of the volcano plot, are found to possess the smallest overpotentials for OER.

\section{Recent progress in SACs for water splitting reactions}

Since Zhang et al. [68] first proposed SACs in 2011, SACs have gained traction, especially in the electrocatalytic field. For
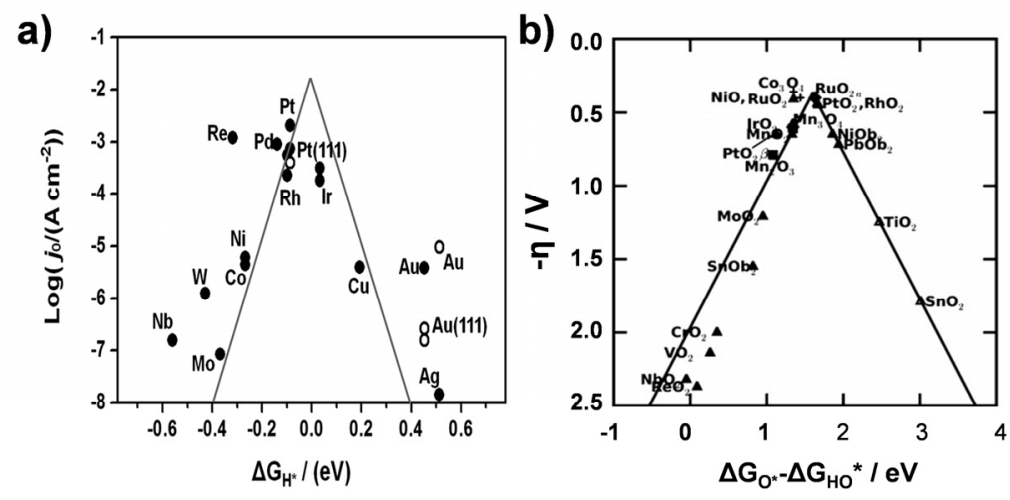

Fig. 1. Activity trends towards hydrogen evolution (a) and oxygen evolution (b). Panel (a) reprinted with permission from ref. [64] Copyright 2015, The Royal Society of Chemistry. Panel (b) reprinted with permission from Ref. [67] Copyright 2011, Wiley-VCH Verlag GmbH \& Co. KGaA, Weinheim. 
electrochemical water splitting, several SACs have exhibited remarkable catalytic abilities, as shown in Table 1. According to the type of support used, SACs can be classified into three cat- egories, namely, alloy-based SACs, carbon-based SACs, and SACs supported on other compounds. In this section, each of these types of SACs is discussed in some detail.

Table 1

Recent progress in SACs for electrochemical water splitting.

\begin{tabular}{|c|c|c|c|c|}
\hline Reaction & Catalyst & Electrolyte & Overpotential & Ref. \\
\hline & $\mathrm{Ir}_{1} @ \mathrm{Co} / \mathrm{NC}$ & $1 \mathrm{M} \mathrm{KOH}$ & $0.060 \mathrm{~V} @ 10 \mathrm{~mA} \mathrm{~cm}^{-2}$ & [37] \\
\hline & Ru-NC-700 & $1 \mathrm{M} \mathrm{KOH}$ & $0.012 \mathrm{~V} @ 10 \mathrm{~mA} \mathrm{~cm}-2$ & [41] \\
\hline & A-Ni@DG & $0.5 \mathrm{M} \mathrm{H}_{2} \mathrm{SO}_{4}$ & $0.070 \mathrm{~V} @ 10$ mA cm-2 & [49] \\
\hline & $\mathrm{Pt}_{1} / \mathrm{MC}$ & $0.5 \mathrm{M} \mathrm{H}_{2} \mathrm{SO}_{4}$ & $0.065 \mathrm{~V} @ 100$ mA cm² & [52] \\
\hline & W-SAC & $0.5 \mathrm{M} \mathrm{H}_{2} \mathrm{SO}_{4}$ & 0.105 V @ 10 mA cm-2 & [69] \\
\hline & Pt- $1 \mathrm{~T}^{\prime} \mathrm{MoS}_{2}$ & $0.5 \mathrm{M} \mathrm{H}_{2} \mathrm{SO}_{4}$ & $0.180 \mathrm{~V} @ 10$ mA cm-2 & [70] \\
\hline & & $0.5 \mathrm{M} \mathrm{H}_{2} \mathrm{SO}_{4}$ & 0.027 V @ 10 mA cm-2 & \\
\hline & A-CoPt-NC & $1 \mathrm{M} \mathrm{KOH}$ & $0.050 \mathrm{~V} @ 10 \mathrm{~mA} \mathrm{~cm}-2$ & [71] \\
\hline & $\mathrm{Pt} / \mathrm{np}-\mathrm{Co}_{0.85} \mathrm{Se}$ & $1 \mathrm{M}$ phosphate buffer solutions (PBS) & 0.050V@10 mA cm-2 & [72] \\
\hline & & $0.5 \mathrm{M} \mathrm{H}_{2} \mathrm{SO}_{4}$ & 0.077V @@100 mA cm-2 & \\
\hline & $\mathrm{Mo}_{2} \mathrm{TiC}_{2} \mathrm{~T}_{x}-\mathrm{Pt}_{\mathrm{SA}}$ & 0.5 M PBS & $0.061 \mathrm{~V} @ 10$ mA cm-2 & [73] \\
\hline & Pt/p-MWCNTs & $0.5 \mathrm{M} \mathrm{H}_{2} \mathrm{SO}_{4}$ & $0.044 \mathrm{~V} @ 10$ mA cm-2 & [74] \\
\hline & & $1 \mathrm{M} \mathrm{KOH}$ & $0.098 \mathrm{~V} @ 10$ mA cm-2 & \\
\hline & $\mathrm{NISA}^{-\mathrm{IMOS}_{2}}$ & $0.5 \mathrm{M} \mathrm{H}_{2} \mathrm{SO}_{4}$ & $0.110 \mathrm{~V} @ 10 \mathrm{~mA} \mathrm{~cm}-2$ & [/5] \\
\hline & & $1 \mathrm{M} \mathrm{KOH}$ & $0.007 \mathrm{~V} @ 10$ mA cm-2 & \\
\hline & Ru@Co-SAs/N-C & $0.5 \mathrm{M} \mathrm{H}_{2} \mathrm{SO}_{4}$ & $0.057 \mathrm{~V} @ 10$ mA cm-2 & [76] \\
\hline & & $1 \mathrm{M}$ PBS & $0.055 \mathrm{~V} @ 10 \mathrm{~mA} \mathrm{~cm}-2$ & \\
\hline & ALD50Pt/NGNs & $0.5 \mathrm{M} \mathrm{H}_{2} \mathrm{SO}_{4}$ & $0.050 \mathrm{~V} @ 16 \mathrm{~mA} \mathrm{~cm}-2$ & [77] \\
\hline & $\mathrm{Ni} / \mathrm{GD}$ & $0.5 \mathrm{M} \mathrm{H}_{2} \mathrm{SO}_{4}$ & $0.088 \mathrm{~V} @ 10 \mathrm{~mA} \mathrm{~cm}{ }^{-2}$ & \\
\hline \multirow[t]{30}{*}{ HER } & $\mathrm{Fe} / \mathrm{GD}$ & $0.5 \mathrm{M} \mathrm{H}_{2} \mathrm{SO}_{4}$ & $0.066 \mathrm{~V} @ 10 \mathrm{~mA} \mathrm{~cm}-2$ & [78] \\
\hline & $\mathrm{Pt}_{1} / \mathrm{hNCNC}-2.92$ & $0.5 \mathrm{M} \mathrm{H}_{2} \mathrm{SO}_{4}$ & $0.015 \mathrm{~V} @ 10 \mathrm{~mA} \mathrm{~cm}-2$ & [79] \\
\hline & $\mathrm{Co}_{1} / \mathrm{PCN}$ & $1 \mathrm{M} \mathrm{KOH}$ & $0.138 \mathrm{~V} @ 10 \mathrm{~mA} \mathrm{~cm}-2$ & [80] \\
\hline & SANi-PtNWs & $1 \mathrm{M} \mathrm{KOH}$ & 0.070 V@11mA cm-2 & [81] \\
\hline & Co-substituted Ru & $1 \mathrm{M} \mathrm{KOH}$ & $0.013 \mathrm{~V} @ 11 \mathrm{~mA} \mathrm{~cm}-2$ & [82] \\
\hline & $\mathrm{Pt}_{1} / \mathrm{OLC}$ & $0.5 \mathrm{M} \mathrm{H}_{2} \mathrm{SO}_{4}$ & 0.038V @ 11mA cm-2 & [83] \\
\hline & RuAu-0,2 & $1 \mathrm{M} \mathrm{KOH}$ & 0.024V @@11mA cm-2 & [84] \\
\hline & $\mathrm{Fe}-\mathrm{N}_{4} \mathrm{SAs} / \mathrm{NPC}$ & $1 \mathrm{M} \mathrm{KOH}$ & $0.202 \mathrm{~V} @ 10 \mathrm{~mA} \mathrm{~cm}-2$ & [85] \\
\hline & PtSA-NT-NF & $1 \mathrm{M}$ PBS & $0.024 \mathrm{~V} @ 10 \mathrm{~mA} \mathrm{~cm}-2$ & [86] \\
\hline & RuSAs@PN & $0.5 \mathrm{M} \mathrm{H}_{2} \mathrm{SO}_{4}$ & $0.024 \mathrm{~V} @ 10 \mathrm{~mA} \mathrm{~cm}-2$ & [87] \\
\hline & $\mathrm{Cu} @ \mathrm{MoS}_{2}$ & $0.5 \mathrm{M} \mathrm{H}_{2} \mathrm{SO}_{4}$ & $0.131 \mathrm{~V} @ 10$ mA cm-2 & [88] \\
\hline & & $1 \mathrm{M} \mathrm{KOH}$ & $0.041 \mathrm{~V} @ 10$ mA cm-2 & \\
\hline & $\mathrm{Ru}-\mathrm{MoS}_{2} / \mathrm{CC}$ & $0.5 \mathrm{M} \mathrm{H}_{2} \mathrm{SO}_{4}$ & $0.061 \mathrm{~V} @ 10$ mA cm-2 & [89] \\
\hline & & $1 \mathrm{M}$ PBS & $0.114 \mathrm{~V} @ 10$ mA cm-2 & \\
\hline & Pt SASs/AG & $0.5 \mathrm{M} \mathrm{H}_{2} \mathrm{SO}_{4}$ & $0.012 \mathrm{~V} @ 10$ mA cm-2 & [90] \\
\hline & CoSAs/PTF-600 & $0.5 \mathrm{M} \mathrm{H}_{2} \mathrm{SO}_{4}$ & $0.094 \mathrm{~V} @ 10 \mathrm{~mA} \mathrm{~cm}-2$ & [91] \\
\hline & & $1 \mathrm{M} \mathrm{KOH}$ & $0.178 \mathrm{~V} @ 10 \mathrm{~mA} \mathrm{~cm}-2$ & \\
\hline & SACo-N/C & $0.5 \mathrm{M} \mathrm{H}_{2} \mathrm{SO}_{4}$ & $0.169 \mathrm{~V} @ 10 \mathrm{~mA} \mathrm{~cm}-2$ & [92] \\
\hline & RuSA-N-S- $\mathrm{Ti}_{3} \mathrm{C}_{2} \mathrm{~T}_{x}$ & $0.5 \mathrm{M} \mathrm{H}_{2} \mathrm{SO}_{4}$ & $0.151 \mathrm{~V} @ 10 \mathrm{~mA} \mathrm{~cm}-2$ & [93] \\
\hline & $\mathrm{Mo}_{1} \mathrm{~N}_{1} \mathrm{C}_{2}$ & $0.1 \mathrm{M} \mathrm{KOH}$ & $0.132 \mathrm{~V} @ 10$ mA cm-2 & [94] \\
\hline & $\mathrm{Ir}_{1} @ \mathrm{Co} / \mathrm{NC}$ & $1 \mathrm{M} \mathrm{KOH}$ & $0.260 \mathrm{~V} @ 10 \mathrm{~mA} \mathrm{~cm}^{-2}$ & [37] \\
\hline & Ru-N-C & $0.5 \mathrm{M} \mathrm{H}_{2} \mathrm{SO}_{4}$ & $0.267 \mathrm{~V} @ 10 \mathrm{~mA} \mathrm{~cm}-2$ & [40] \\
\hline & CoIr-0.2 & $1 \mathrm{M}$ PBS & $0.373 \mathrm{~V} @ 10 \mathrm{~mA} \mathrm{~cm}-2$ & [42] \\
\hline & A-Ni@DG & $1 \mathrm{M} \mathrm{KOH}$ & $0.270 \mathrm{~V} @ 10 \mathrm{~mA} \mathrm{~cm}-2$ & [49] \\
\hline & $\mathrm{P}-\mathrm{O} / \mathrm{FeN}_{4}-\mathrm{CNS}$ & $0.1 \mathrm{M} \mathrm{KOH}$ & $0.390 \mathrm{~V} @ 10 \mathrm{~mA} \mathrm{~cm}-2$ & [54] \\
\hline & $\mathrm{Fe}-\mathrm{N}_{4} \mathrm{SAs} / \mathrm{NPC}$ & $1 \mathrm{M} \mathrm{KOH}$ & $0.440 \mathrm{~V} @ 10 \mathrm{~mA} \mathrm{~cm}-2$ & [85] \\
\hline & $\mathrm{Au} @ \mathrm{Ni}_{2} \mathrm{P}-350^{\circ} \mathrm{C}$ & $1 \mathrm{M} \mathrm{KOH}$ & $0.240 \mathrm{~V} @ 10 \mathrm{~mA} \mathrm{~cm}-2$ & [95] \\
\hline & Co- $\mathrm{C}_{3} \mathrm{~N}_{4} @ \mathrm{CS}$ & $1 \mathrm{M} \mathrm{KOH}$ & $0.470 \mathrm{~V} @ 50 \mathrm{~mA} \mathrm{~cm}-2$ & [96] \\
\hline & Co-Fe-N-C. & $1 \mathrm{M} \mathrm{KOH}$ & $0.309 \mathrm{~V} @ 10 \mathrm{~mA} \mathrm{~cm}-2$ & [97] \\
\hline & $\mathrm{Co}-\mathrm{C}_{3} \mathrm{~N}_{4} / \mathrm{CNT}$ & $1 \mathrm{M} \mathrm{KOH}$ & $0.380 \mathrm{~V} @ 10$ mA cm-2 & [98] \\
\hline \multirow[t]{11}{*}{ OER } & CoNi-SAs/NC & $1 \mathrm{M} \mathrm{KOH}$ & $0.340 \mathrm{~V} @ 10 \mathrm{~mA} \mathrm{~cm}-2$ & [99] \\
\hline & $A u_{1} N_{x}$ & $0.1 \mathrm{M} \mathrm{KOH}$ & $0.450 \mathrm{~V} @ 10 \mathrm{~mA} \mathrm{~cm}-2$ & [100] \\
\hline & $\mathrm{w}-\mathrm{Ni}(\mathrm{OH})_{2}$ & $1 \mathrm{M} \mathrm{KOH}$ & $0.273 \mathrm{~V} @ 10$ mA cm-2 & [101] \\
\hline & Ni-NHGF & $1 \mathrm{M} \mathrm{KOH}$ & $0.331 \mathrm{~V} @ 10$ mA cm-2 & [102] \\
\hline & $\mathrm{Ru}_{1}-\mathrm{Pt}_{3} \mathrm{Cu}$ & $0.1 \mathrm{M} \mathrm{HClO}_{4}$ & $0.220 \mathrm{~V} @ 10 \mathrm{~mA} \mathrm{~cm}-2$ & [103] \\
\hline & $\mathrm{Ru} / \mathrm{CoFe}-\mathrm{LDH}$ & $1 \mathrm{M} \mathrm{KOH}$ & $0.198 \mathrm{~V} @ 10 \mathrm{~mA} \mathrm{~cm}-2$ & [104] \\
\hline & 0.5 wt $\% \mathrm{Pt} / \mathrm{NiO}$ & $1 \mathrm{M} \mathrm{KOH}$ & $0.358 \mathrm{~V} @ 10$ mA cm-2 & [105] \\
\hline & Ir@Co & $1 \mathrm{M} \mathrm{KOH}$ & $0.273 \mathrm{~V} @ 10$ mA cm-2 & [106] \\
\hline & HCM@Ni-N. & $1 \mathrm{M} \mathrm{KOH}$ & $0.304 \mathrm{~V} @ 10$ mA cm-2 & [107] \\
\hline & SCoNC & $0.1 \mathrm{M} \mathrm{KOH}$ & $0.310 \mathrm{~V} @ 10 \mathrm{~mA} \mathrm{~cm}-2$ & [108] \\
\hline & Co-N $x /$ C NRA & $0.1 \mathrm{M} \mathrm{KOH}$ & $0.300 \mathrm{~V} @ 10$ mA cm-2 & [109] \\
\hline
\end{tabular}




\subsection{Alloy-based SACs}

Alloy-based SACs, in which metal substrates are employed for trapping and supporting other single metal atoms, have been utilized for both HER and OER. These metal substrates are considered to provide surface defects which fix the foreign metal atoms, while modulating the electronic structure of the foreign metal atoms via ligand effects and strain effects. After doping other metal atoms into metal substrates, these catalysts are translated to alloys, which combine the properties for alloy catalysts and SACs, leading to remarkable activities that are significantly higher than those of typical alloy catalysts [76,82,106,110-113]. For HER, Pt-based catalysts are regarded as the most effective catalysts. Duan et al. [81] decorated the surface of platinum nanowires with single nickel atoms through an alloying process, followed by a partial electrochemical dealloying process. These decorated single nickel atoms, binding with two hydroxyl groups, function like $\mathrm{Ni}(\mathrm{OH})_{2}$ to modulate the electronic structure of the Pt surface. The mass activity value for single nickel atom-doped platinum nanowires (SANi-PtNWs) reaches $11.8 \mathrm{~A} \mathrm{mgPt}^{-1}$, which is almost 17 times that of the mass activity value corresponding to Pt/C. In addition, the reduced Tafel slope is found to have a value of $60.3 \mathrm{mV}$

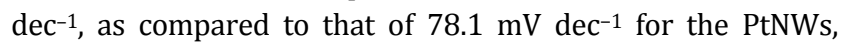
which confirms that the modification induced by single nickel atoms enhances HER kinetics. Besides, single platinum atoms may also be anchored on other metal substrates. Single platinum atoms have been alloyed into $\mathrm{Cu}$-doped palladium nanorings in which copper was also present as single atoms [114]. Thus, the dual sites consisting of single copper atoms and single platinum atoms are known to coexist, synergistically promoting the activity for HER. The as-prepared catalyst exhibits outstanding HER performance with a high mass current density of $3002 \mathrm{~A} \mathrm{~g}_{(\mathrm{Pd}+\mathrm{Pt})^{-1}}$ at an overpotential of $-0.05 \mathrm{~V}$. Apart from platinum, other non-platinum metals have also been doped into metal substrates with atomic dispersion. Du et al. [84] alloyed $\mathrm{Au}$ atoms into a $\mathrm{Ru}$ substrate. Relatively few $\mathrm{Au}$ atoms were found to be necessary to effectively modify the structure of the Ru substrate, resulting in a superior HER activity, as compared to that of Pt/C catalysts. As for OER, single Ru atoms have been trapped by different $\mathrm{Pt} / \mathrm{Cu}$ alloy supports through sequential acid etching and electrochemical leaching [103]. Wu et al. [103] discovered that the electronic structure of single $\mathrm{Ru}$ sites could be modified by modulating the compressive strain of the metal substrates. Thus, the binding energy of the oxygenated species on the single $\mathrm{Ru}$ sites could be tailored to an optimum level, so that an excellent OER performance can be achieved. In acid medium, single $\mathrm{Ru}$ atoms supported on $\mathrm{Pt} / \mathrm{Cu}$ alloy deliver $90 \mathrm{mV}$ lower overpotential at a current density of $10 \mathrm{~mA} \mathrm{~cm}^{-2}\left(\eta_{10}\right)$. Additionally, the Ru SACs possess a longer lifetime than commercial $\mathrm{RuO}_{2}$. Even after 28 $\mathrm{h}$ of continuous electrolysis, there is little change in $\eta_{10}$ for $\mathrm{Ru}$ SACs, indicating that the increased SMSI between the Ru atoms and the metal substrate is strong enough to restrict the dissolution of $\mathrm{Ru}$ atoms in a harsh acid medium. This result provides new insight for solving the problem of poor durability of the OER catalysts in acid medium, suggesting a broad range of ap- plications for SACs.

Typically, these alloy-based SACs are used as unsupported catalysts in chemical reactions. In electrochemical reactions, however, conductive additives are always required when alloy-based SACs are used. These could partly block the active centers and eventually cause some loss of activity. Besides, the loading of the single metal atoms is very small, which is restricted by the concentration of defects on the metal or alloy substrate. In addition, the alloy structure is thermally stable. If the loading of the single metal atoms was much higher, the single metal atoms would be able to easily aggregate together to alloy with the metal substrate. Hence, in principle, it is difficult for metal substrates to anchor significant amounts of single metal atoms without aggregation.

\subsection{Carbon-based SACs}

Carbon materials have been widely employed as substrates for catalysts [79,86,115-121]. In general, carbon materials possess intrinsic structure defects, besides which external dopants (heteroatoms or surface functional groups) provide many accessible sites for the deposition of metal atoms. These sites play the role of ligands to tightly anchor the metal atoms and retard their aggregation. After being loaded on the carbon matrix, metal atoms may bond with the carbon matrix or the surface functional groups to form new active centers for the reactions, resulting in a superior catalytic performance of carbon-based SACs. Among all the carbon materials, nitrogen-doped carbon attracts a lot of attention for applications involving SACs [122-126]. Nitrogen doping effectively breaks the electric neutrality of the carbon matrix. As a result, the more electronegative nitrogen atoms coordinate with the single metal atoms to form a M- $\mathrm{N}_{x}$ structure which has been confirmed to be the active center for several electrochemical reactions [80,127-132]. Many carbon-based SACs with single $\mathrm{M}-\mathrm{N}_{x}$ sites have been widely exploited as a consequence. Zeolitic imidazolate frameworks (ZIFs) are commonly used as the precursors for the synthesis of carbon-based SACs owing to their distinct $\mathrm{M}-\mathrm{N}_{X}$ structures, which can inhibit the migration and agglomeration of the metal atoms [133-137]. Chen et al. [138] used Zn/Co bimetallic ZIFs as the precursors with the assistance of dimethyl sulfoxide (DMSO) to fabricate single cobalt atom catalysts, confirming that the dominant activity for HER is due to the presence of the Co- $\mathrm{N}_{x}$ sites [138]. In order to increase the loading amount of the single atoms, $\mathrm{KCl}$ particles were chosen as the seeds for the growth of ZIFs to assist in the synthesis of SAC (Fig. 2(a)) [108]. The Co loading of as-prepared SAC reaches $15.3 \mathrm{wt} \%$, so that this SAC shows excellent OER performance, even surpassing that of $\mathrm{IrO}_{2}$ catalysts. Guo et al. [139] also employed ZIFs to prepare SACs. In contrast to previous studies, single atoms were anchored on a monolith, which could be fabricated as the electrode without any binders. The as-prepared electrode with single cobalt atom sites exhibits a small overpotential of $400 \mathrm{mV}$ of $\eta_{10}$ for OER (Fig. 2(b)).

Apart from ZIFs, other materials with defined $\mathrm{M}-\mathrm{N}_{x}$ structures, for example, metallic polyphthalocyanine, have also been 

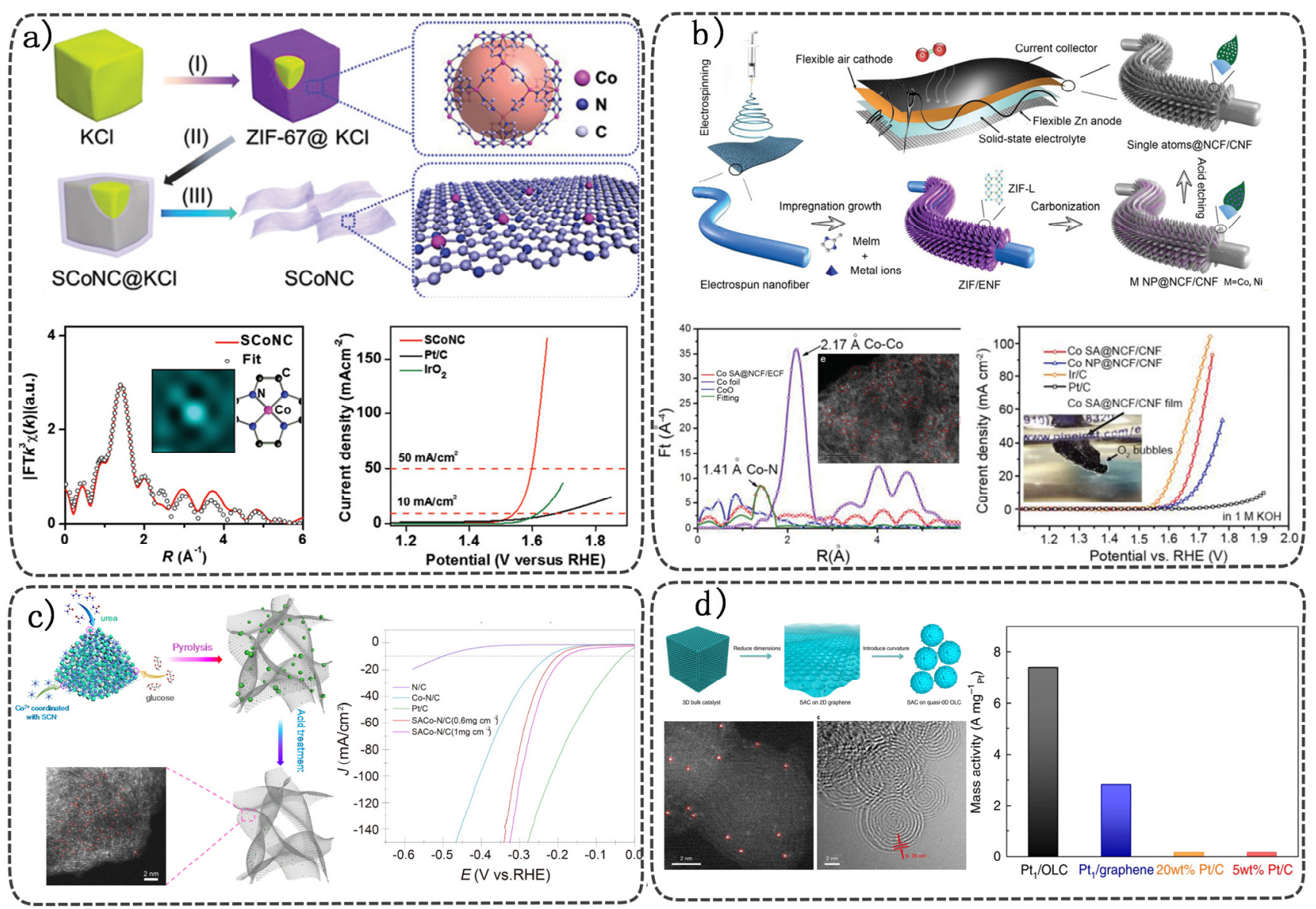

Fig. 2. (a) The synthetic procedure, the EXAFS spectra of the Co K-edge and OER performance of cobalt-based SACs by using KCl particles as the growth seeds; reprinted with permission from Ref. [108] Copyright 2019, WILEY-VCH Verlag GmbH \& Co. KGaA, Weinheim. (b) The synthetic procedure, the EXAFS spectra of the Co K-edge and OER performance of SACs electrode without any binders; reprinted with permission from Ref. [139] Copyright 2011, WILEY-VCH Verlag GmbH \& Co. KGaA, Weinheim. (c) The synthetic procedure, HAADF-STEM image and HER performance of cobalt based SACs prepared by $\mathrm{Co}^{2+} \mathrm{SCN}^{-}$compound and $\mathrm{C}_{3} \mathrm{~N}_{4}$ precursors; reprinted with permission from Ref. 92 Copyright 2019, Science China Press. Published by Elsevier B.V. and Science China Press. (d) The HER performance of single platinum atoms supported on single-wall carbon nanotubes and the adsorption of Pt onto $(14,0)$ SWNT and graphene. Reprinted with permission from Ref. [151] Copyright 2017, American Chemical Society.

used as the precursors for carbon-based SACs [85,91,140-143]. Chen et al. [144] proposed a polymerization-pyrolysis-evaporation approach to synthesize carbon-based SACs with atomically dispersed $\mathrm{Fe}^{-\mathrm{N}_{4}}$ sites, by using bimetallic $\mathrm{Zn} / \mathrm{Fe}$ polyphthalocyanine as the precursor. The dispersed $\mathrm{Fe}-\mathrm{N}_{4}$ sites are confirmed to enhance both HER and OER kinetics. For the overall water-splitting, this catalyst only needs a low potential of $1.67 \mathrm{~V}$ to drive a current of $10 \mathrm{~mA}$ $\mathrm{cm}^{-2}$. Besides, $\mathrm{C}_{3} \mathrm{~N}_{4}$ is also a superior precursor for anchoring the single metal atoms to fabricate carbon-based SACs with atomically dispersed $M-\mathrm{N}_{x}$ sties [96,100,145-147]. Qiao et al. [98] investigated a series of $\mathrm{M}-\mathrm{C}_{3} \mathrm{~N}_{4}$ catalysts, demonstrating that $\mathrm{C}_{3} \mathrm{~N}_{4}$ could be a platform for single metal atoms. Considering the necessary conductivity, $\mathrm{C}_{3} \mathrm{~N}_{4}$ could be hard to satisfy the demand for the electrocatalysts. Wei et al. [92] used the $\mathrm{C}_{3} \mathrm{~N}_{4}$ precursor to isolate the single cobalt atoms to produce SACs with atomically dispersed Co- $\mathrm{N}_{x}$ sites (Fig. 2(c)). In the synthesis process, the $\mathrm{Co}^{2+}-\mathrm{SCN}^{-}$compound facilitates the separation of to the process of cobalt particle formation from the carbon deposition process, enabling the cobalt atoms to thermally mi- grate to $\mathrm{C}_{3} \mathrm{~N}_{4}$-derived carbon with high nitrogen content to generate SACs. The as-prepared catalyst exhibits an overpotential of $198 \mathrm{mV}$ to reach a current density of $10 \mathrm{~mA} \mathrm{~cm}-2$.

Sometimes, the single metal atoms may be loaded onto the carbon materials directly $[74,77,78,148,149]$. Chen et al. [150] proposed a chemical vapor deposition strategy by using nanoporous $\mathrm{Ni}$ as the template. The as-prepared catalyst, with a porous structure similar to that of the template, was characterized by high-angle annular dark-field scanning transmission electron microscopy (HAADF-STEM), indicating that single nickel atoms had been loaded on the graphene. The single nickel sites exhibit remarkable HER activities $(\eta=50 \mathrm{mV})$, which is confirmed by both experimental and theoretical investigations. Laasonen et al. [151] reported single-walled carbon nanotubes (SWNT) with atomically-dispersed platinum for HER, prepared via a facile electrochemical deposition, as shown in Fig. 2(d). Theoretical calculations suggested that the SWNT sidewall can efficiently immobilize Pt atoms, owing to its curved structure. Song et al. [83] have also reported that curved carbon supports can efficiently anchor atomically-dispersed platinum. They 
further found that the Pt atom is tightly bonded to a surface $\mathrm{C}$ atom and two $\mathrm{O}$ atoms on an onion-like carbon, resulting in a very high energy barrier for the diffusion of platinum atoms. Thus, the stable individual platinum atoms on the onion-like carbon exhibit excellent activity towards HER in terms of a low overpotential $(\eta=38 \mathrm{mV})$ and a high turnover frequency ( $40.78 \mathrm{H}_{2} \mathrm{~s}^{-1}$ at $100 \mathrm{mV}$ ). Also, the graphene, with the help of aniline molecules, could effectively restrict the agglomeration of platinum atoms; thus, SAC with atomically-dispersed platinum was obtained [90]. The mass activity of this catalyst has been shown to attain a value of $22400 \mathrm{~A} \mathrm{~g}_{\mathrm{Pt}^{-1}}$ at $\eta=50 \mathrm{mV}$, which is 46 times higher than that of $20 \mathrm{wt} \% \mathrm{Pt} / \mathrm{C}$ catalyst.

Although great progress has been made in carbon-based SACs, they are not very well understood. Firstly, despite using the same metal, SACs developed by different methods significantly differ from each other. Secondly, for carbon-based SACs, there may coexist the active centers covering the heteroatoms doped sites and the metal atom sites. In such systems, it could be challenging to identify the actual active center that is significant for the catalytic process. Thirdly, the synthesis of carbon-based SACs still involves trial and error methods [152-156]. It is highly desirable, but challenging, to realize precise control of the coordination environment of the metal active centers.

\subsection{SACs supported on other compounds}

The single metal atoms are also immobilized in other compound supports, such as oxides, sulfides, hydroxides, etc. $[72,87,104,157-160]$. In all these compound supports the surface defects (cation defects and anion defects) are the predominant sites for trapping single metal atoms. Owing to the differences between the substrate and the single metal atoms, the trapping of the single metal atoms may affect the compound, making it more active in certain reactions. Jiang et al. [105] reported that single platinum atoms were incorporated into the crystalline phase of $\mathrm{NiO}$ nanocubes with $0.5 \mathrm{wt} \%$ platinum loading (Fig. 3(a)). The doped platinum atoms effectively increase the phase transformation rate of $\mathrm{NiO}$ to $\mathrm{NiOOH}$ by weakening the local $\mathrm{Ni}-\mathrm{O}$ bonds in $\mathrm{NiO}$, resulting in an enhancement of OER activity for $\mathrm{NiO}$ catalysts. In this catalyst, single platinum atoms are not the direct active centers, but function as the cocatalyst. Coincidentally, the single metal atoms may also be activated by the surrounding environment.
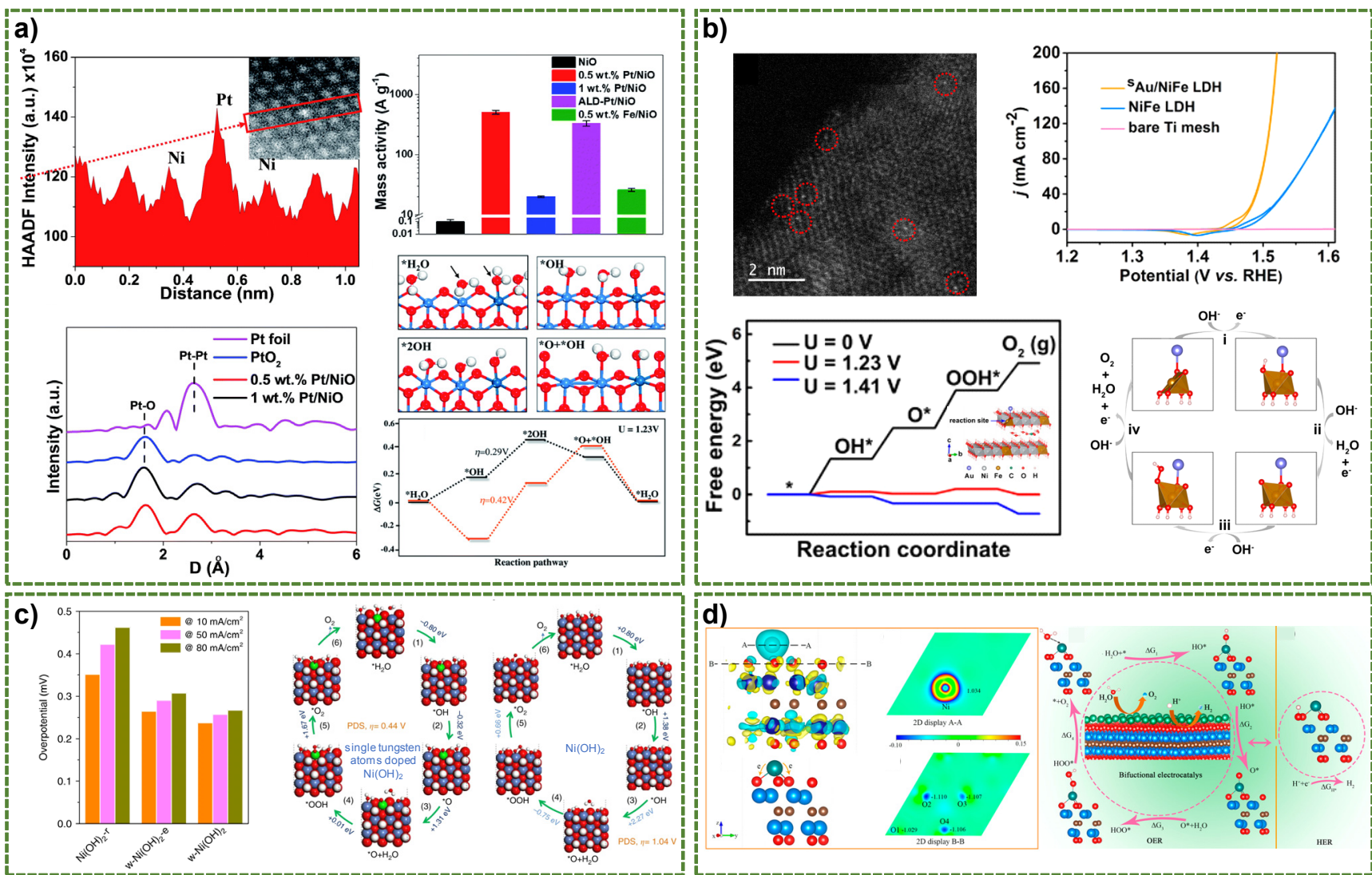

Fig. 3. (a) HAADF signal analysis, EXAFS spectra of the Pt K-edge 0 and mass activity for $0.5 \mathrm{wt} \% \mathrm{Pt} / \mathrm{Ni}$, and simulated OER element steps proceeded at the Pt-doped $\gamma-\mathrm{NiOOH}$ and the corresponding energy profiles of the OER at $1.23 \mathrm{~V}$. Reprinted with permission from Ref. [105] Copyright 2018, The Royal Society of Chemistry. (b) HAADF-STEM and OER performance for single gold atoms-doped $\mathrm{NiFe}(\mathrm{OH})_{2}$, and simulated OER element steps and the corresponding energy profiles on the surface of single gold atoms-doped $\mathrm{NiFe}(\mathrm{OH})_{2}$. Reprinted with permission from Ref. [161] Copyright 2018, American Chemical Society. (c) The OER performance of single tungsten atoms-doped $\mathrm{Ni}(\mathrm{OH})_{2}$ nanosheets, and simulated OER element steps and the corresponding energy profiles for single tungsten atoms-doped $\mathrm{Ni}(\mathrm{OH})_{2}$ nanosheets and $\mathrm{Ni}(\mathrm{OH})_{2}$ nanosheets. Reprinted with permission from Ref. [101] Copyright 2019, Springer Nature. (d) The charge density difference on the $\mathrm{Ni} / \mathrm{Cr}_{2} \mathrm{CO}_{2}$ surface and the schematic of the single metal atoms anchored on $\mathrm{Cr}_{2} \mathrm{CO}_{2}$ surface for overall water splitting. Reprinted with permission from Ref. [165] Copyright 2019, American Chemical Society. 
Single gold atoms were also observed to enhance the OER occuring on $\mathrm{NiFe}(\mathrm{OH})_{2}$ and $\mathrm{Ni}_{2} \mathrm{P}$. In fact, $0.4 \mathrm{wt} \%$ gold with atomic dispersion decoration resulted in a 6-fold OER activity enhancement for Ni/Fe layered double hydroxide (LDH) [161]. The doped $\mathrm{Au}$ atoms altered the distribution of charge density, thus facilitating the whole OER process, especially the rate determining step (RDS) from $\mathrm{O}^{*}$ to $\mathrm{OOH}^{*}$, as illustrated in Fig. 3(b). $\mathrm{Gu}$ et al. [95] reported that the OER activity of $\mathrm{Ni}_{2} \mathrm{P}$ increased significantly when gold atoms were doped into the $\mathrm{Ni}_{2} \mathrm{P}$ crystal structure. The OER activity of this gold atoms-doped $\mathrm{Ni}_{2} \mathrm{P}$ catalyst even surpasses $\mathrm{IrO}_{2}$ catalysts by a factor of $16 . \mathrm{MoS}_{2}$ has been extensively researched as a catalyst for HER [70,75,88-89,162-164]. Single metal atoms have been also doped into the $\mathrm{MoS}_{2}$ matrix to improve its HER activity.

However, there is an alternative view that the single atoms could also be the active centers. By using $\mathrm{Ni}(\mathrm{OH})_{2}$ as the support, Ma et al. [101] synthesized single tungsten atoms-doped $\mathrm{Ni}(\mathrm{OH})_{2}$ nanosheets. Density functional theory calculations confirmed that the first three steps of OER occurred on the single tungsten atom sites were exothermic reactions. As shown in Fig. 3(c), the $\mathrm{d}^{0} \mathrm{~W}^{6+}$ atom with a low spin-state could effectively stabilize the $0^{*}$ intermediate, resulting in a low overpotential for the generation of the $\mathrm{OOH}^{*}$ species, starting from $0^{*}$. This only requires an overpotential of $237 \mathrm{mV}$ at $\eta_{10}$. MXene, with a general formula of $\mathrm{M}_{n+1} \mathrm{X}_{n} \mathrm{~T}_{x}$, was also employed for stabilizing the single atoms $[73,93,165,166]$. Zhang et al. [165] investigated both OER and HER activities of single metal atoms in the $\mathrm{Cr}_{2} \mathrm{CO}_{2}$ matrix. The electron transfer from $\mathrm{Ni}$ to $\mathrm{Cr}_{2} \mathrm{CO}_{2}$ strengthens the binding energy between them, thus stabilizing the nickel atoms immobilized on the $\mathrm{Cr}_{2} \mathrm{CO}_{2}$ surface, resulting in an excellent performance for water splitting (Fig. 3(d)). Wang et al. [73] immobilized platinum atoms into the Mo vacancies in $\mathrm{Mo}_{2} \mathrm{TiC}_{2} \mathrm{~T}_{x}$ MXene, and reported that the as-prepared catalyst possesses a much higher mass activity and a superior stability for HER than the commercial platinum-on-carbon catalyst, owing to strong covalent interactions between the positively charged Pt single atoms and MXene.

As mentioned above, the surface defects present in the support matrix seem to play a significant role in the immobilization of single metal atoms. Clearly, the quantity of the defects present is likely to limit the loading amount for single metal atoms. It is, therefore, necessary to quantify the influence of the defects in the support matrices in term of the types of defects present, as well as their concentrations, on the fabrication and performance of SACs.

\section{Factors influencing the performance of SACs}

Although SACs have been the focus of recent research, a good understanding of the active centers present in the SACs, as well as the factors that could affect their activities for HER and OER is essential for applications in electrochemical water splitting. In this section, the influence of four factors on the HER and OER activities of SACs have been summarized, including the inherent element property, the coordination environment, the geometric structure and the loading amount of metal atoms.

\subsection{The inherent element property}

It is well known that each element has its own chemical properties. When the single metal atom is considered to be the active site, different single metal atoms featured with different atomic structures may demonstrate different activities [167-172]. Duan et al. [102] reported an approach using graphene oxide to fabricate atomic $3 d$ metal atoms embedded in nitrogen-doped holey graphene frameworks (M-NHGFs). A series of M-NHGFs with different $3 d$ metal atoms have been successfully synthesized. It was found from the atomistic structures of M-NHGFs that the $\mathrm{MN}_{4} \mathrm{C}_{4}$ fragment unambiguously determines their electrocatalytic activity towards OER. An activity trend of M-NHGFs for OER following the ordering Ni $>$ Co $>$ Fe has been proven by electrochemical investigations. Density functional theoretical predictions further demonstrated that the differences in activities among the M-NHGFs is attributable to the different $d$-orbital configurations of the metals. It was observed that not only did the free energy of absorption of the intermediates change with the increase in the number of $\mathrm{d}$ electrons of the metal in the $\mathrm{MN}_{4} \mathrm{C}_{4}$ structure, but there was also a change in the reaction pathway. Compared to the single site mechanism for Co-NHGFs and Fe-NHGFs, a dual-site mechanism with a smallest limiting barrier of $0.42 \mathrm{eV}$ is observed for Ni-NHGFs, indicating that the properties of SACs depend on the identity of the metal centers and their interactions with the coordination configuration. Du et al. [173] calculated the activities of SACs for both HER and OER by using graphdiyne as the support. It was found that Pt@graphdiyne and Ni@graphdiyne exhibit the smallest overpotentials for HER and OER, respectively (Fig. 4(a) and 4(b)). Also, the $\mathrm{C}_{9} \mathrm{~N}_{4}$ monolayer was explored as a support for SACs by Wang et al. [174]. After single metal atom doping into the support, a strong hybridization between the $\mathrm{p}$ orbital of nitrogen atoms and $\mathrm{d}$ orbital of metal atoms is observed, confirming the interaction due to charge transfer between the metal atom and the $\mathrm{C}_{9} \mathrm{~N}_{4}$ monolayer support. Since the atomic structure of the metal atoms is different, this interaction is different for different metal atoms, leading to distinct adsorption free energies for $\mathrm{H}$ and $\mathrm{OH}$ and thereby, disparate activities for both HER and OER.

Sometimes the support for single metal atoms can be considered to be the active component. Doping single metal atoms would modulate the activity of the support matrix through the strong metal-support interaction. Thus, this interaction may be different for different metal SACs with the same support, resulting in distinct activities. Bao et al. [175] investigated a series of single metal atom-doped $\mathrm{MoS}_{2}\left(\mathrm{M}-\mathrm{MoS}_{2}\right)$ catalysts for HER. They found that the transition metal atoms could replace the Mo atoms in the $\mathrm{MoS}_{2}$ matrix. Some of the metal atoms with less d electrons would replace Mo atoms to bond with six $\mathrm{S}$ atoms, while the others with more d electrons would bond with four $S$ atoms. As shown in Fig. 4(c), after doping single metal atoms into the $\mathrm{MoS}_{2}$ matrix, the electronic structure for $\mathrm{S}$ sites adjacent to the doped single metal atoms could be tuned; thus, the adsorption behavior of $\mathrm{H}$ atoms on these sites could be modulated, resulting in a significantly enhanced HER activity on the $\mathrm{MoS}_{2}$ surface. Such a difference would result in very 
a)

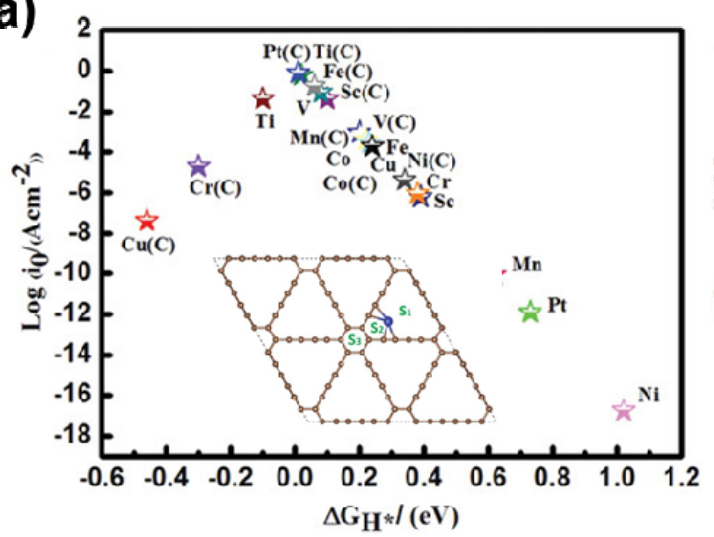

c)

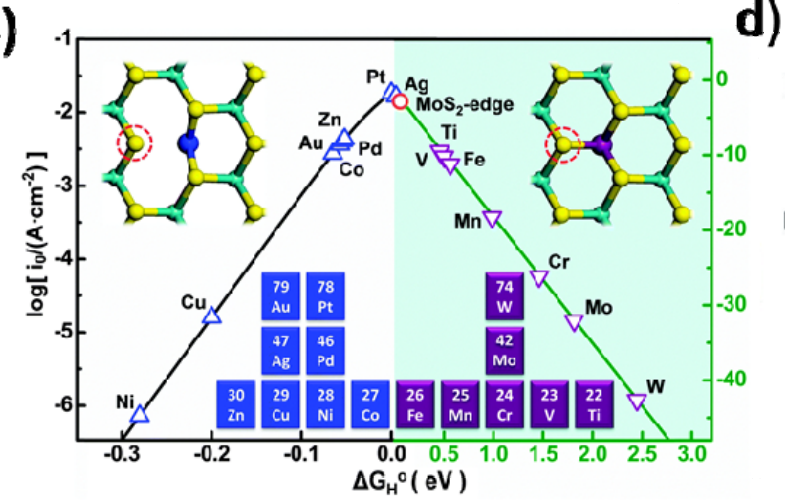

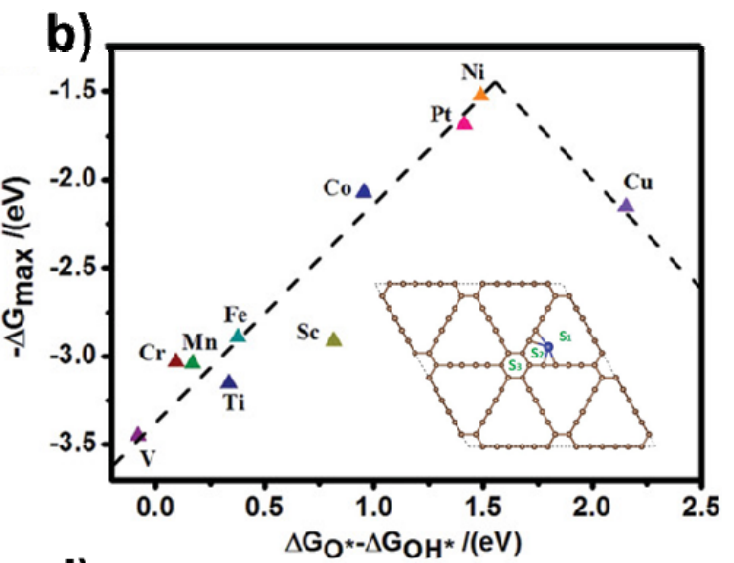

d)
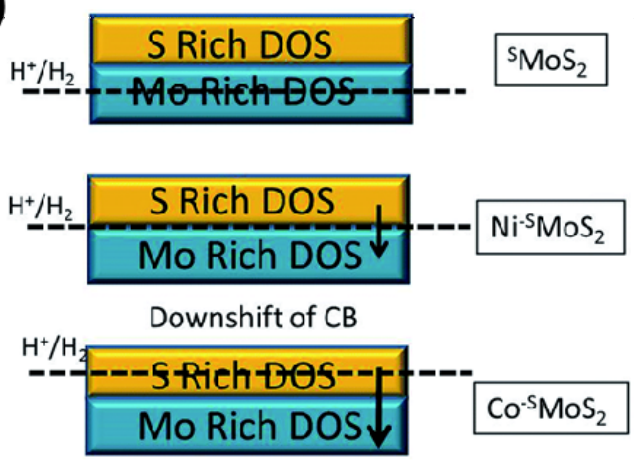

Fig. 4. (a) The volcano curve of exchange current as a function of the Gibbs free energy for hydrogen binding on different active sites on the GDY monolayer. (b) Activity trends toward OER, the negative maximum potential-determining step was plotted against the $\left(\Delta G_{0^{*}}-\Delta G_{\mathrm{OH}^{*}}\right)$ step; reproduced with permission from Ref. [173] Copyright 2019 WILEY-VCH Verlag GmbH \& Co. KGaA, Weinheim. (c) The relation between currents (log(i0)) and $\Delta G_{\mathrm{H}^{*}}$ indicates a volcano curve. Reprinted with permission from Ref. [175] Copyright 2015, The Royal Society of Chemistry. (d) Downshift of the conduction band (CB) upon addition of a single Co and Ni metal atom at the Mo atop site, respectively. Reprinted with permission from Ref. [176] Copyright 2018, The Royal Society of Chemistry.

different adsorption behaviors of $\mathrm{H}$ atoms and subsequently, different HER activities. Tsang et al. [176] discovered that different single atom-doped monolayer $\mathrm{MoS}_{2}$ nanosheets may have disparate effects on HER activity. Compared to octahedrally coordinated $3 d^{8} \mathrm{Ni}^{2+}, 3 d^{7} \mathrm{Co}^{2+}$ can only be tetrahedrally coordinated with sulfide ligands. This tetrahedrally coordinated Co can only affect neighboring S sites, but has absolutely no influence on Mo sites with a larger downshifting on both the $\mathrm{S}-3 p$ and Mo- $4 d$ components in the conduction band (CB), resulting in a reduction of $\Delta G_{\mathrm{H}^{*}}$ towards the value of zero, thereby enhancing the HER process. On the contrary, octahedrally coordinated Ni can affect both neighboring $\mathrm{S}$ sites and Mo sites, leading to little downshifting on both the S- $3 p$ and Mo- $4 d$ components in the CB. The interaction between Ni-Mo, in particular, can increase the value of $\Delta G_{\mathrm{H}^{*}}$ away from the value of zero, which could eventually be detrimental for the HER process (Fig. 4(d)).

These results demonstrated that both the structural and electronic factors can be modulated by doping different metal atoms. An appropriate element selection for the doping metal may be one of the key points to achieve high activities for both HER and OER. Even so, the varieties of the SACs are too broad to investigate one by one. It is necessary to correlate the interactions between the atomic structure of the doping metal and the support, and determine how it could affect the activity of the SAC. If possible, a descriptor about this interaction should be established to get an insight into the development of a controlled design of SACs.

\subsection{The coordination environment}

Apart from the inherent element property, the coordination environment is also likely to affect the activities of SACs [71,177-184]. For example, in the case of carbon-based SACs, the metal atoms could be doped into the carbon matrix directly to form $\mathrm{M} @ \mathrm{C}_{X}$ structures; or, they could be doped into the nitrogen traps with different coordination numbers to produce $M @ N_{X}$ structures [185,186]. It is clear that distinctly different structures will exhibit significantly different activities. Chou et al. [37] analyzed the possible local structure of a single iridium atom in Ir@Co/NC catalysts. The single iridium atom was found to exhibit different activities for both HER and OER, depending on the coordination environment it is embedded in. The high OER performance is attributed to the Ir@CoO structure, while the superior HER efficiency is ascribed to the formation of the Ir@NC3 structure. Gao et al. [187] reported that the coordination number of the metal atom determines the adsorption strength for the intermediates $\left(\mathrm{H}_{\mathrm{ads}}\right.$ and $\left.\mathrm{OH}_{\mathrm{ads}}\right)$ on the single 
metal atom-doped graphene catalysts for HER and OER, respectively. The single metal atom with a lower coordination number at the edge demonstrates the highest catalytic activity for HER. In contrast, a higher coordinated single metal atom exhibits the optimum OER performance. Thus, Ni@1-zigzag and Ni@N4 structure are found to have the lowest overpotentials for HER and OER, respectively, as shown in Fig. 5(a) and 5(b). Zeng et al. [188] factored in the electronegativity of the nearest neighbor atoms, and proposed a parameter, $\varphi$, to describe the intrinsic properties of the carbon-based SACs, including the coordination atoms, the electronegativity of the metal atom, as well as its coordination atoms. More importantly, the absorption properties of the intermediate species are also included in this parameter. This work [188] highlights the potential to use the parameter $\varphi$ to develop carbon-based SACs with a high electrocatalytic performance for water splitting and also provides the insight to establish similar parameters to describe SACs with other supports.

Apart from the different doping sites, the effect of the external environment, which means the SACs with or without modulation, may also change the coordination environment, even for SACs with the same coordination on the same sites. It is reported that Pt sites would be poisoned after a carbon monoxide treatment. However, when the size of Pt is reduced to an atomic level, a promoting effect induced by carbon monoxide for HER is observed [189]. That is, after modulation with carbon monoxide, the Pt- $\mathrm{S}_{4}$ center exhibits enhanced activity for HER (Fig. 5(c)). XANES results and theoretical calculations both demonstrated that carbon monoxide, which is a strong $\pi$-acceptor, withdraws electrons from the Pt center. As a result, the Pt center became more electrophilic, facilitating the Volmer step. This work [189] expands the application of ligation technology from homogeneous catalysis to heterogeneous electrocatalysis, offering a pathway for further optimizing the structure of SACs.

Moreover, the different elements present in one SAC may also affect each other to create a completely new coordination environment, as compared to an SAC that contains a single element [190-193]. These dual or multi-element-doped SACs always exhibit superior catalytic performances, as compared to those of SACs that contain only one element. Hu et al. [97] have shown that Co-Fe double-atom catalyst can be obtained from a single-atom Co catalyst by incorporating $\mathrm{Fe}$ atoms into the Co-N-C matrix, which on being dispersed at the atomic level,
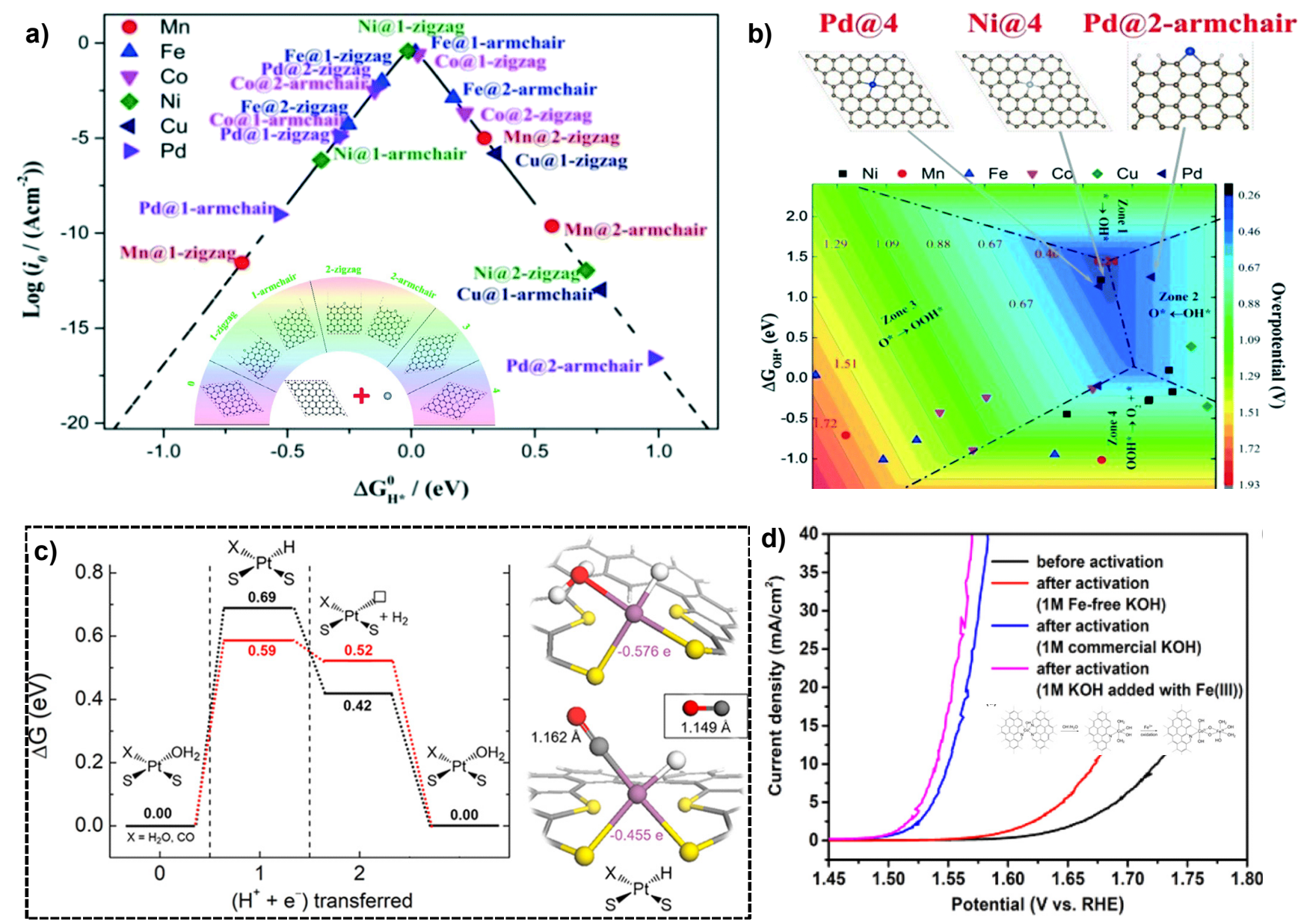

Fig. 5. The HER volcano curve (a) and OER volcano plot (b) for various low-coordinated transition metals/graphene composite. Reprinted with permission from Ref. [187] Copyright 2017, The Royal Society of Chemistry. (c) Gibbs free energy diagram of HER and DFT optimized geometry of Pt-S4 complexes in the presence of water (black) and CO (red). Reprinted with permission from Ref. [189] Copyright 2018, American Chemical Society. (d) OER performance of Co-Fe double-atom catalyst; Inset: proposed model for the formation of Co-Fe double-atom catalyst. Reprinted with permission from Ref. [97] Copyright 2019, American Chemical Society. 
form Co-Fe moieties using one or two bridging OH groups. As expected, this Co-Fe moiety is reported to have a significantly higher turnover frequency, as compared to that of metal oxides for OER (Fig. 5(d)). Similarly, the synergistic effect of neighboring atomically-dispersed Co-Ni dual metal centers was confirmed to be beneficial to the adsorption of $\mathrm{OH}$, eventually optimizing the reversible oxygen electrocatalysis [99]. However, for these catalysts, the interactions between different elements is still not well understood. Also, the model for the structure may also be too simple in that it does not reflect the real atomic structure perfectly; this makes it difficult to comprehensively model the catalytic processes involved.

\subsection{The geometric structure}

The geometric structure of an electrocatalyst determines the distribution of active sites. A catalytically efficient structure would be one in which all the active sites are exposed and accessible [109,194-202]. For SACs, although the metal atom utilization could be $100 \%$, some of the active metal sites may be embedded, so that the practical utilization efficiency of active metal sites is still far from $100 \%$. Many strategies have been developed to optimize the structure of SACs, so as to be able to construct more accessible interfaces, in order to achieve efficient utilization of the active metal sites. Wei et al. [203] engineered a single cobalt atom on self-supported nanosheet arrays (NSAs) architecture (SS-Co-SAC) via a two-step procedure consisting of the rational synthesis of the precursors, followed by a pyrolysis treatment. SS-Co-SAC exhibits an ultrathin sheet-like nanostructure which grew regularly on carbon cloth (Figs. 6(a) and 6(b)). The value of $\eta_{10}$ for OER for SS-Co-SAC is much lower than that of the SACs with bulk or stacked nanosheet morphology, which is attributed to its structural geometry. Li et al. [94] used $\mathrm{SiO}_{2}$ as a template to fabricate the single Mo atom catalyst (Mo-SAC). The specific surface area of as-prepared Mo-SAC is about $583 \mathrm{~m}^{2} \mathrm{~g}^{-1}$. As shown in Fig 6(c) and 6(d), the TEM images indicate that it contains a highly open porous structure. The onset overpotential ( $\left.\eta_{\text {onset }}\right)$ of Mo-SAC is measured to be about $13 \mathrm{mV}$, which is comparable to that of $\mathrm{Pt} / \mathrm{C}$ catalysts. Also, $\eta_{10}$ is found to be only $132 \mathrm{mV}$ for this structure. Lou et al. [107] constructed an isolated Ni and hollow carbon matrix decorated with N atoms (HCM@Ni-N). This hollow structure is believed to expose more active sites to the triphase interface, resulting in a superior OER activity (Fig. 6(e) and 6(f)). However, in spite of significant progress in SACs for water splitting, there are not many reported studies regarding geometric structure optimization for SACs, probably because it is different to modulate the structure, while also maintaining the metal in an atomically dispersed state. It is highly desirable to develop the strategies to synthesize SACs with superior structural characteristics.

\subsection{The loading amount of metal atoms}

In spite of having an optimal geometric structure that effectively exposes the active sites, the number of active sites for SACs is still dependent on the amount of metal atoms loaded in
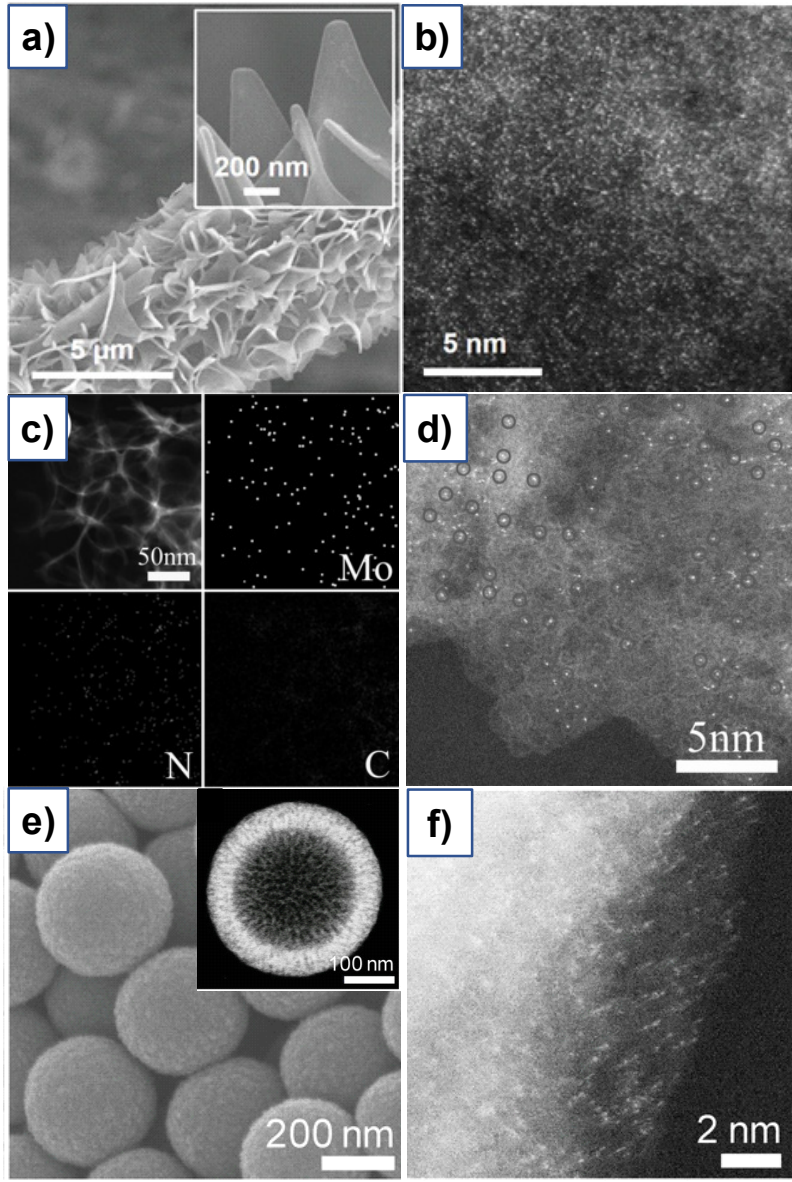

Fig. 6. SEM (a) and HAADF-STEM (b) images of SS-Co-SAC NSAs. Reprinted with permission from Ref. [203] Copyright 2019, Wiley-VCH Verlag GmbH \& Co. KGaA, Weinheim. (c) TEM image and the corresponding EDS maps of Mo-SAC. (d) HAADF-STEM images of Mo-SAC. Reprinted with permission from Ref. [94] Copyright 2017, Wiley-VCH Verlag GmbH \& Co. KGaA, Weinheim. (e) FESEM and ADF-STEM image of HCM@Ni-N. (f) HAADF-STEM image of HCM@Ni-N. Reprinted with permission from Ref. [107] Copyright 2019, Wiley-VCH Verlag GmbH \& Co. KGaA, Weinheim.

the SAC, which determines the activity of the SAC. A higher loading amount of metal atoms in SACs implies the presence of more available active centers, which may result in a superior catalytic performance of SACs [86,108,130,195,199,204-209]. Song et al. [42] reported that an atom of iridium incorporated in cobalt hydroxide catalyst with $9.7 \mathrm{wt} \%$ Ir content exhibits an OER catalytic performance with a value of $373 \mathrm{mV}$ for $\eta_{10}$ in 1.0 $\mathrm{M}$ phosphate buffer solution, significantly outperforming the commercial $\mathrm{IrO}_{2}$ catalysts. An excellent performance for HER is also achieved by catalysts with relatively high platinum loading amounts (3.8 wt\%), as reported by Wang and coworkers [204]. However, it is known to be an enormous challenge to synthesize SACs with high loading amounts of metal atoms. The enormous specific surface energy of single metal atoms makes agglomeration very facile. When many metal atoms have been loaded onto the surface of the substrates, they are always observed to aggregate into nanocluster particles rather than be dispersed as single metal atoms. Typically, SACs are obtained by atomic layer deposition (ALD), chemical vapor deposition 
a)

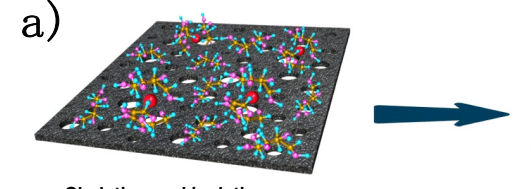

Chelation and isolation

M-NC SAC

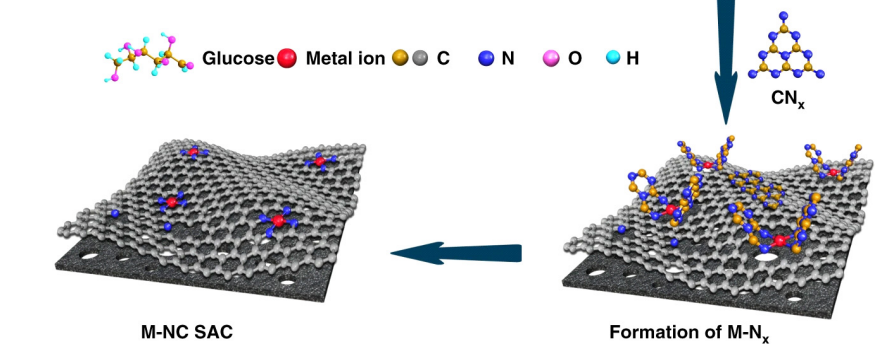

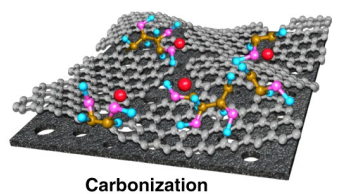

Carbonization

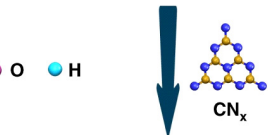

c)

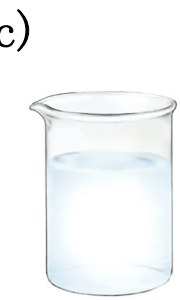

$\mathrm{H}_{2} \mathrm{PtCl}_{6}$ solution
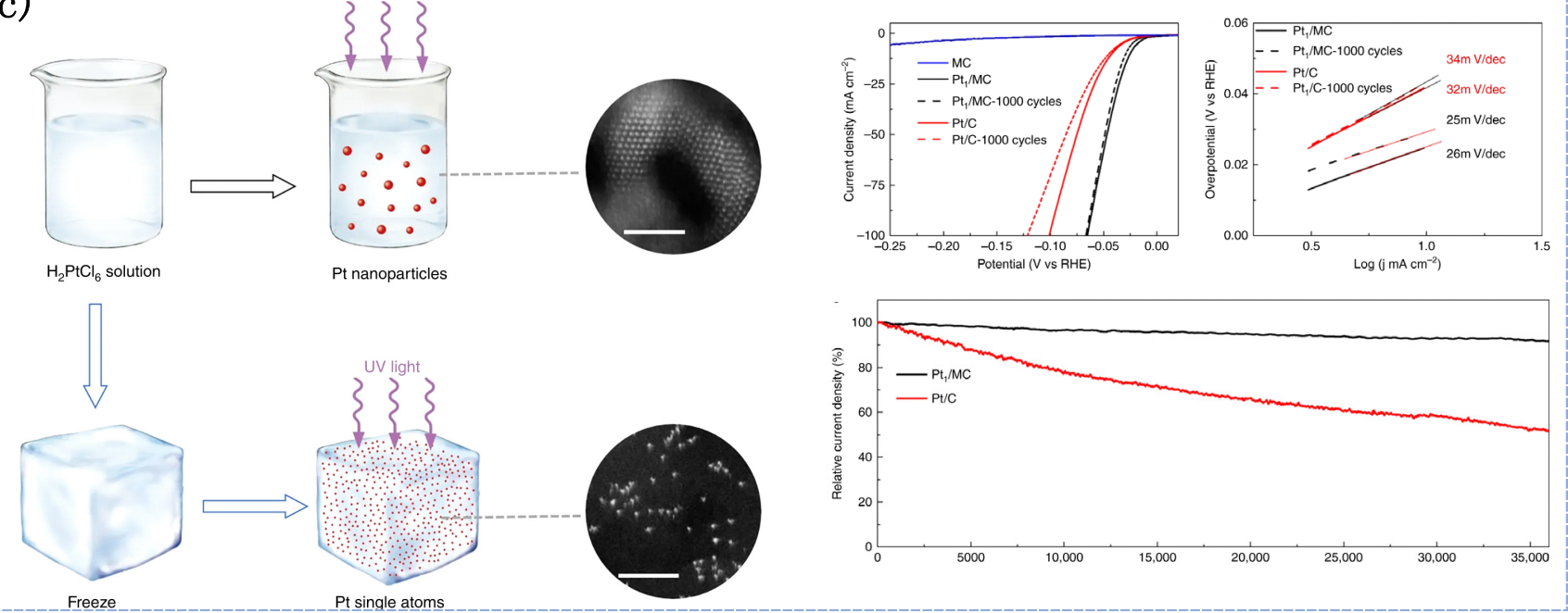

Fig. 7. (a) The cascade anchoring strategy for the synthesis of M-NC SACs. Reprinted with permission from Ref. [48] Copyright 2019, Springer Nature. (b) Six typical configurations of $\left[\mathrm{PtCl}_{6}\right]^{2-}$ on different supports with different nitrogen atoms in micropores and corresponding calculated free energies. Reprinted with permission from Ref. [79] Copyright 2019, Springer Nature. (c) Schematic illustration of the iced-photochemical process and HER performance of the corresponding prepared SACs (scale bar, $2 \mathrm{~nm}$ ). Reprinted with permission from Ref. [52] Copyright 2017, Springer Nature.

(CVD), mass-selected soft-landing method (MSSL), or the wet chemistry method. Compared to the other three methods, the wet chemistry method is regarded as the most effective strategy to fabricate SACs with high loading amounts of metal atoms. Hu et al. [48] reported a quadruple protection tactic to inhibit the agglomeration and sintering of the single atoms (Fig. 7(a)). This quadruple protection tactic elaborately employs both coordination effect and the spatial confinement effect. The metal atoms are tightly fixed on the 0-rich carbon support with high surface area by several glucose ligands and the surroundings are abundant in the active $\mathrm{CN}_{x}$ species derived from melamine, ensuring the atomic dispersion of metal atoms after the calcining process. Thus, single cobalt atoms with a loading amount of about 12 wt $\%$ could be successfully loaded onto the carbon support. Wei et al. [127] successfully fabricated SACs with single zinc atoms. Using a heating rate of $1^{\circ} \mathrm{C} \mathrm{min}-1$, it was possible to achieve a loading amount of zinc atoms up to $9.33 \mathrm{wt} \%$. The as-prepared catalyst shows a high specific surface area, of about $1002 \mathrm{~m}^{2} \mathrm{~g}-1$, which may be another reason why such a high loading could be achieved. The micropores are thought to provide the opportunity to trap the heat-migrated zinc atoms with slow gasification rate. Hu et al. [79] also confirmed that the hierarchical nitrogen-doped carbon nanocages, with a high specific surface area of $877 \mathrm{~m}^{2} \mathrm{~g}-1$, could trap the platinum atoms. However, they propose that a high content of $\mathrm{N}$-dopant is necessary to fix the platinum atoms in the micropores, since there is no high-temperature treatment, (Fig. 7(b)). Therefore, the loading of platinum could be increased to $5.68 \mathrm{wt} \%$. Moreover, iced-photochemical reduction has been developed by $\mathrm{Wu}$ et al. (Fig. 7(c)) [52]. In this method of synthesis, the migration of metal atoms is significantly slowed down; thus, an SAC with about $13 \mathrm{wt} \%$ platinum loading could be obtained, which displays efficient catalytic activity and durability for HER, with an overpotential of only $65 \mathrm{mV}$ to reach a current density of 100 $\mathrm{mA} \mathrm{cm}-2$, which is distinctly superior to the performance of the commercial Pt/C catalyst.

In order to synthesize SACs with high loading amounts of metal atoms using the wet chemistry method, three key points need to be complied with. (1) During the synthesis process, it is necessary to intervene in the nucleation process of the nano- 
particles by using the spatial confinement method or slowing down the migration of the metal atoms. (2) In order to trap as many of the metal atoms as possible, a substrate characterized by a high surface area, with enough micropore structure or a high concentration of surface defects, is desirable. (3) The surface dopants could assist in fixing the metal atoms functioning as the ligands; thus, the surface modulation by the dopants is also essential. However, apart from carbon materials, it is rare to be able to fabricate SACs with high metal loading using other materials as substrates. It is challenging but necessary to develop non-carbon-based SACs with high metal loading. The pilot process during the preparation needs to be investigated in order to explore new methods for the synthesis of SACs with high metal loading.

\section{Summary and Outlook}

To summarize, as the emerging catalysts, SACs offer new insights into the mechanisms of electrochemical reactions. The development of SACs is an important focus of current research, owing to their significance in electrochemical splitting of water. In this review, we have discussed possible mechanisms for HER and OER at the surface of the electrocatalyst. The classification of SACs into three classes, including alloy-based SACs, carbon-based SACs, and SACs supported on other compounds was then described. All these three types of SACs have been investigated, and the as-prepared catalysts are known to exhibit excellent activities toward HER and OER. Different factors affecting the activities of SACs were then discussed, including the inherent element property, the coordination environment, the geometric structure and the loading amount of metal atoms. Recent advances in this frontier provide new insights into the controlled design of SACs.

However, many aspects of SACs need to be investigated further. It is highly desirable to increase the metal loading, and hence the number of active sites, in order to significantly enhance the activities of SACs. Moreover, the rational design of geometric structure of SACs by making most active centers accessible will contribute to increasing their activities. More importantly, different strategies need to be employed to design each type of SAC. Future research should be principally aimed at constructing SACs with high metal loading and optimal geometries, leading to superior catalytic activities. Besides, the nature of the active centers in SACs as well as the details of the reaction mechanisms for different catalytic processes that occur on the surface of SACs are not well-understood till date. Descriptors for each type of SAC could be proposed to further guide the rational design of SACs. Clearly, further experimental and theoretical investigations of highly efficient SACs in water splitting are the need of the hour in order to use them in large-scale applications.

\section{Conflicts of interest}

There are no conflicts to declare.

\section{References}

[1] Y. Jiao, Y. Zheng, M. Jaroniec, S.Z. Qiao, Chem. Soc. Rev., 2015, 44, 2060-2086.

[2] L. S. Peng, S. S. A. Shah, Z. D. Wei, Chin. J. Catal., 2018, 39, 1575-1593.

[3] R. Xiang, L. Peng, Z. Wei, Chem. Eur. J., 2019, 25, 9799-9815.

[4] J. W. Li, Q. N. Zhuang, P. M. Xu, D. W. Zhang, L. C. Wei, D. S. Yuan, Chin. J. Catal., 2018, 39, 1403-1410.

[5] Z. Li, Y. Qi, W. Y. Wang, D. Li, Z. Li, Y.A. Xiao, G.Y. Han, J. R. Shen, C. Li, Chin. J. Catal., 2019, 40, 486-494.

[6] D. Ji, L. Peng, J. Shen, M. Deng, Z. Mao, L. Tan, M. Wang, R. Xiang, J. Wang, S. S. A. Shah, Chem. Commun., 2019, 55, 3290-3293.

[7] L. Peng, X. Zheng, L. Li, L. Zhang, N. Yang, K. Xiong, H. Chen, J. Li, Z. Wei, Appl. Catal. B, 2019, 245, 122-129.

[8] L. Peng, J. Wang, Y. Nie, K. Xiong, Y. Wang, L. Zhang, K. Chen, W. Ding, L. Li, Z. Wei, ACS Catal., 2017, 7, 8184-8191.

[9] X. Zheng, L. Peng, L. Li, N. Yang, Y. Yang, J. Li, J. Wang, Z. Wei, Chem. Sci., 2018, 9, 1822-1830.

[10] K. Xiong, L. Huang, Y. Gao, H. Zhang, Y. Zhuo, H. Shen, Y. Wang, L. Peng, Z. Wei, Electrochem. Commun., 2018, 92, 9-13.

[11] L. Peng, J. Shen, X. Zheng, R. Xiang, M. Deng, Z. Mao, Z. Feng, L. Zhang, L. Li, Z. Wei, J. Catal., 2019, 369, 345-351.

[12] L. Lu, L. Peng, L. Li, J. Li, X. Huang, Z. Wei, J. Energy Chem., 2020, 40,

\section{Graphical Abstract}

Chin. J. Catal., 2021, 42: 1269-1286 doi: 10.1016/S1872-2067(20)63619-1

\section{Recent developments in the use of single-atom catalysts for water splitting}

Yao Wang, Xun Huang *, Zidong Wei

Sichuan University; Chongqing University

Three classes of single atom catalysts (SACs) for water splitting, including alloy-based SACs, carbon-based SACs and SACs with other supports, as well as the factors affecting their activity have been summarized.

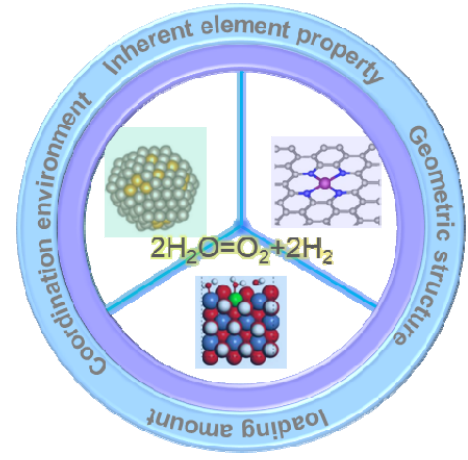


52-56.

[13] P. F. Cheng, T. Feng, Z. W. Liu, D. Y. Wu, J. Yang, Chin. J. Catal., 2019, 40, 1147-1152.

[14] X. P. Liu, S. F. Deng, P. F. Liu, J. N. Liang, M. X. Gong, C. L. Lai, Y. Lu, T. H. Zhao, D. L. Wang, Sci. Bull., 2019, 64, 1675-1684.

[15] R. Xiang, Y. Duan, L. Peng, Y. Wang, C. Tong, L. Zhang, Z. Wei, Appl. Catal. B, 2019, 246, 41-49.

[16] R. Xiang, Y. Duan, C. Tong, L. Peng, J. Wang, S.S.A. Shah, T. Najam, X. Huang, Z. Wei, Electrochim. Acta, 2019, 302, 45-55.

[17] R. Xiang, C. Tong, Y. Wang, L. Peng, Y. Nie, L. Li, X. Huang, Z. Wei, Chin. J. Catal., 2018, 39, 1736-1745.

[18] Y. Wang, W. Ding, S. Chen, Y. Nie, K. Xiong, Z. Wei, Chem. Commun.S, 2014, 50, 15529-15532.

[19] M. Ming, Y. Zhang, C. He, L. Zhao, S. Niu, G. Fan, J. S. Hu, Small, 2019, 15, e1903057.

[20] Q. Wang, M. Ming, N. Shuai, Z. Yun, G. Fan, J. Hu, Adv. Energy Mater., 2018, 8, 1801698.

[21] J. Wang, Z. Li, Y. Wu, Y. Li, Adv. Mater., 2018, 30, e1801649.

[22] Y. Cheng, S. He, S. Lu, J. P. Veder, B. Johannessen, L. Thomsen, M. Saunders, T. Becker, R. De Marco, Q. Li, S. Z. Yang, S. P. Jiang, Adv. Sci., 2019, 6, 1802066.

[23] W. Chen, Y. Ma, F. Li, L. Pan, W. Gao, Q. Xiang, W. Shang, C. Song, P. Tao, H. Zhu, X. Pan, T. Deng, J. Wu, Adv. Funct. Mater., 2019, 29, 1904278.

[24] J. Li, L. Zhong, L. Tong, Y. Yu, Q. Liu, S. Zhang, C. Yin, L. Qiao, S. Li, R. Si, J. Zhang, Adv. Funct. Mater., 2019, 29, 1905423.

[25] J. Liu, M. Jiao, B. Mei, Y. Tong, Y. Li, M. Ruan, P. Song, G. Sun, L. Jiang, Y. Wang, Z. Jiang, L. Gu, Z. Zhou, W. Xu, Angew. Chem. Int. Ed., 2019, 58, 1163-1167.

[26] J. Yang, Z. Qiu, C. Zhao, W. Wei, W. Chen, Z. Li, Y. Qu, J. Dong, J. Luo, Z. Li, Y. Wu, Angew. Chem. Int. Ed., 2018, 57, 14095-14100.

[27] Y. Tang, C. Asokan, M. Xu, G. W. Graham, X. Pan, P. Christopher, J. Li, P. Sautet, Nat. Commun., 2019, 10, 4488.

[28] B. H. Lee, S. Park, M. Kim, A. K. Sinha, S. C. Lee, E. Jung, W. J. Chang, K. S. Lee, J. H. Kim, S. P. Cho, H. Kim, K. T. Nam, T. Hyeon, Nat. Mater., 2019, 18, 620-626.

[29] Y. Qu, Z. Li, W. Chen, Y. Lin, T. Yuan, Z. Yang, C. Zhao, J. Wang, C. Zhao, X. Wang, F. Zhou, Z. Zhuang, Y. Wu, Y. Li, Nat. Catal., 2018, 1, 781-786.

[30] Z. Zhang, X. Gao, M. Dou, J. Ji, F. Wang, Small, 2017, 13, 1604290.

[31] G. Righi, R. Magri, A. Selloni, J. Phys. Chem. C, 2019, 123, 9875-9883.

[32] Y. Guo, S. Mei, K. Yuan, D.-J. Wang, H.-C. Liu, C.-H. Yan, Y.-W. Zhang, ACS Catal., 2018, 8, 6203-6215.

[33] X. J. Cui, X. C. Dai, A. E. Surkus, K. Junge, C. Kreyenschulte, G. Agostini, N. Rockstroh, M. Beller, Chin. J. Catal., 2019, 40, 1679-1685.

[34] K. Xiong, L. Li, L. Zhang, W. Ding, L. Peng, Y. Wang, S. Chen, S. Tan, Z. Wei, J. Mater. Chem. A, 2015, 3, 1863-1867.

[35] X. Sun, M. Liu, Y. Huang, B. Li, Z. Zhao, Chin. J. Catal., 2019, 40, 819-825.

[36] J. N. Tiwari, A. M. Harzandi, M. Ha, S. Sultan, C. W. Myung, H. J. Park, D. Y. Kim, P. Thangavel, A. N. Singh, P. Sharma, S. S. Chandrasekaran, F. Salehnia, J. W. Jang, H. S. Shin, Z. Lee, K. S. Kim, Adv. Energy Mater., 2019, 9, 1900931.

[37] W. H. Lai, L. F. Zhang, W. B. Hua, S. Indris, Z. C. Yan, Z. Hu, B. Zhang, Y. Liu, L. Wang, M. Liu, R. Liu, Y. X. Wang, J. Z. Wang, Z. Hu, H. K. Liu, S. L. Chou, S. X. Dou, Angew. Chem. Int. Ed., 2019, 58, 11868-11873.

[38] Q. Zuo, T. Liu, C. Chen, Y. Ji, X. Gong, Y. Mai, Y. Zhou, Angew. Chem. Int. Ed., 2019, 58, 10198-10203.

[39] J. Xing, J. F. Chen, Y. H. Li, W. T. Yuan, Y. Zhou, L. R. Zheng, H. F.
Wang, P. Hu, Y. Wang, H. J. Zhao, Y. Wang, H. G. Yang, Chem. Eur. J, 2014, 20, 2138-2144.

[40] L. Cao, Q. Luo, J. Chen, L. Wang, Y. Lin, H. Wang, X. Liu, X. Shen, W. Zhang, W. Liu, Z. Qi, Z. Jiang, J. Yang, T. Yao, Nat. Commun., 2019, $10,4849$.

[41] B. Lu, L. Guo, F. Wu, Y. Peng, J. E. Lu, T. J. Smart, N. Wang, Y. Z. Finfrock, D. Morris, P. Zhang, N. Li, P. Gao, Y. Ping, S. Chen, Nat. Commun., 2019, 10, 631.

[42] Y. Zhang, C. Wu, H. Jiang, Y. Lin, H. Liu, Q. He, S. Chen, T. Duan, L. Song, Adv. Mater., 2018, 30, e1707522.

[43] Z. Wang, S.-M. Xu, Y. Xu, L. Tan, X. Wang, Y. Zhao, H. Duan, Y.-F. Song, Chem. Sci., 2019, 10, 378-384.

[44] C. Zhu, Q. Shi, B. Z. Xu, S. Fu, G. Wan, C. Yang, S. Yao, J. Song, H. Zhou, D. Du, S. P. Beckman, D. Su, Y. Lin, Adv. Energy Mater., 2018, 8, 1801956.

[45] P. Chen, T. Zhou, L. Xing, K. Xu, Y. Tong, H. Xie, L. Zhang, W. Yan, W. Chu, C. Wu, Y. Xie, Angew. Chem. Int. Ed., 2017, 56, 610-614.

[46] Y. Zhao, T. Ling, S. Chen, B. Jin, A. Vasileff, Y. Jiao, L. Song, J. Luo, S.-Z. Qiao, Angew. Chem. Int. Ed., 2019, 58, 12252-12257.

[47] Y. Chen, S. Ji, S. Zhao, W. Chen, J. Dong, W. C. Cheong, R. Shen, X. Wen, L. Zheng, A. I. Rykov, S. Cai, H. Tang, Z. Zhuang, C. Chen, Q. Peng, D. Wang, Y. Li, Nat. Commun., 2018, 9, 5422.

[48] L. Zhao, Y. Zhang, L. B. Huang, X. Z. Liu, Q. H. Zhang, C. He, Z. Y. Wu, L. J. Zhang, J. Wu, W. Yang, L. Gu, J. S. Hu, L. J. Wan, Nat. Commun. 2019, 10, 1278.

[49] L. Zhang, Y. Jia, G. Gao, X. Yan, N. Chen, J. Chen, M. T. Soo, B. Wood, D. Yang, A. Du, X. Yao, Chem, 2018, 4, 285-297.

[50] J. Tian, D. Yang, J. Wen, A. S. Filatov, Y. Liu, A. Lei, X. M. Lin, Nanoscale, 2018, 10, 1047-1055.

[51] M. D. Hossain, Z. Liu, M. Zhuang, X. Yan, G.-L. Xu, C. A. Gadre, A. Tyagi, I. H. Abidi, C.-J. Sun, H. Wong, A. Guda, Y. Hao, X. Pan, K. Amine, Z. Luo, Adv. Energy Mater., 2019, 9, 1803689.

[52] H. Wei, K. Huang, D. Wang, R. Zhang, B. Ge, J. Ma, B. Wen, S. Zhang, Q. Li, M. Lei, C. Zhang, J. Irawan, L. M. Liu, H. Wu, Nat. Commun., 2017, 8, 1490.

[53] X. Mao, L. Zhang, G. Kour, S. Zhou, S. Wang, C. Yan, Z. Zhu, A. Du, ACS Appl. Mater. Interfaces, 2019, 11, 17410-17415.

[54] H. Sun, S. Liu, M. Wang, T. Qian, J. Xiong, C. Yan, ACS Appl. Mater. Interfaces, 2019, 11, 33054-33061.

[55] N. Xuan, J. Chen, J. Shi, Y. Yue, P. Zhuang, K. Ba, Y. Sun, J. Shen, Y. Liu, B. Ge, Z. Sun, Chem. Mater., 2018, 31, 429-435.

[56] C. Wu, X. Zhang, Z. Xia, M. Shu, H. Li, X. Xu, R. Si, A. I. Rykov, J. Wang S. Yu, S. Wang, G. Sun, J. Mater. Chem. A, 2019, 7, 14001-14010.

[57] C. Zhu, Q. Shi, S. Feng, D. Du, Y. Lin, ACS Energy Lett., 2018, 3, 1713-1721.

[58] Y. Peng, B. Lu, S. Chen, Adv. Mater., 2018, 30, e1801995.

[59] S. Sultan, J. N. Tiwari, A. N. Singh, S. Zhumagali, M. Ha, C. W. Myung, P. Thangavel, K. S. Kim, Adv. Energy Mater., 2019, 9, 1900624.

[60] H. Liu, X. Peng, X. Liu, ChemElectroChem, 2018, 5, 2963-2974.

[61] J. Kim, H. E. Kim, H. Lee, ChemSusChem, 2018, 11, 104-113.

[62] Y. N. Chen, X. Zhang, Z. Zhou, Small Methods, 2019, 3, 1900050.

[63] J. Zhang, C. Liu, B. Zhang, Small Methods, 2019, 3, 1800481.

[64] M. Zeng, Y. Li, J. Mater. Chem. A, 2015, 3, 14942-14962.

[65] J. K. Nørskov, T. Bligaard, A. Logadottir, J. R. Kitchin, J. G. Chen, S. Pandelov, U. Stimming, J. Electrochem. Soc., 2005, 152, J23-J26.

[66] J. Rossmeisl, Z. W. Qu, H. Zhu, G. J. Kroes, J. K. Norskov, J. Electroanal. Chem., 2007, 607, 83-89.

[67] I. C. Man, H. Y. Su, F. Calle-Vallejo, H. A. Hansen, J. I. Martínez, N. G. Inoglu, J. Kitchin, T. F. Jaramillo, J. K. Nørskov, J. Rossmeisl, ChemCatChem, 2011, 3, 1159-1165.

[68] B. Qiao, A. Wang, X. Yang, L. F. Allard, Z. Jiang, Y. Cui, J. Liu, J. Li, T. Zhang, Nat. Chem., 2011, 3, 634-641. 
[69] W. Chen, J. Pei, C. T. He, J. Wan, H. Ren, Y. Wang, J. Dong, K. Wu, W. C. Cheong, J. Mao, X. Zheng, W. Yan, Z. Zhuang, C. Chen, Q. Peng, D. Wang, Y. Li, Adv. Mater., 2018, 30, e1800396.

[70] C. Wu, D. Li, S. Ding, Z. U. Rehman, Q. Liu, S. Chen, B. Zhang, L. Song, J. Phys. Chem. Lett., 2019, 10, 6081-6087.

[71] L. Zhang, Y. Jia, H. Liu, L. Zhuang, X. Yan, C. Lang, X. Wang, D. Yang, K. Huang, S. Feng, X. Yao, Angew. Chem. Int. Ed., 2019, 58, 9404-9408.

[72] K. Jiang, B. Liu, M. Luo, S. Ning, M. Peng, Y. Zhao, Y. R. Lu, T. S. Chan, F. M. F. de Groot, Y. Tan, Nat. Commun., 2019, 10, 1743.

[73] J. Zhang, Y. Zhao, X. Guo, C. Chen, C.-L. Dong, R.-S. Liu, C.-P. Han, Y. Li, Y. Gogotsi, G. Wang, Nat. Catal., 2018, 1, 985-992.

[74] J. Ji, Y. Zhang, L. Tang, C. Liu, X. Gao, M. Sun, J. Zheng, M. Ling, C. Liang, Z. Lin, Nano Energy, 2019, 63, 103849.

[75] Q. Wang, Z. L. Zhao, S. Dong, D. He, M. J. Lawrence, S. Han, C. Cai, S. Xiang, P. Rodriguez, B. Xiang, Z. Wang, Y. Liang, M. Gu, Nano Ener$g y$, 2018, 53, 458-467.

[76] S. Yuan, Z. Pu, H. Zhou, J. Yu, I. S. Amiinu, J. Zhu, Q. Liang, J. Yang, D. He, Z. Hu, G. Van Tendeloo, S. Mu, Nano Energy, 2019, 59, 472-480.

[77] N. Cheng, S. Stambula, D. Wang, M. N. Banis, J. Liu, A. Riese, B. Xiao, R. Li, T. K. Sham, L. M. Liu, G. A. Botton, X. Sun, Nat. Commun., 2016, 7, 13638.

[78] Y. Xue, B. Huang, Y. Yi, Y. Guo, Z. Zuo, Y. Li, Z. Jia, H. Liu, Y. Li, Nat. Commun., 2018, 9, 1460.

[79] Z. Zhang, Y. Chen, L. Zhou, C. Chen, Z. Han, B. Zhang, Q. Wu, L. Yang, L. Du, Y. Bu, P. Wang, X. Wang, H. Yang, Z. Hu, Nat. Commun., 2019, $10,1657$.

[80] L. Cao, Q. Luo, W. Liu, Y. Lin, X. Liu, Y. Cao, W. Zhang, Y. Wu, J. Yang, T. Yao, S. Wei, Nat. Catal., 2018, 2, 134-141.

[81] M. Li, K. Duanmu, C. Wan, T. Cheng, L. Zhang, S. Dai, W. Chen, Z. Zhao, P. Li, H. Fei, Y. Zhu, R. Yu, J. Luo, K. Zang, Z. Lin, M. Ding, J. Huang, H. Sun, J. Guo, X. Pan, W. A. Goddard, P. Sautet, Y. Huang, X. Duan, Nat. Catal., 2019, 2, 495-503.

[82] J. Mao, C.-T. He, J. Pei, W. Chen, D. He, Y. He, Z. Zhuang, C. Chen, Q. Peng, D. Wang, Y. Li, Nat. Commun., 2018, 9, 4958.

[83] D. Liu, X. Li, S. Chen, H. Yan, C. Wang, C. Wu, Y.A. Haleem, S. Duan, J. Lu, B. Ge, P. M. Ajayan, Y. Luo, J. Jiang, L. Song, Nat. Energy, 2019, 4, 512-518.

[84] C. H. Chen, D. Wu, Z. Li, R. Zhang, C. G. Kuai, X. R. Zhao, C. K. Dong, S. Z. Qiao, H. Liu, X. W. Du, Adv. Energy Mater., 2019, 9, 1803913.

[85] Y. Pan, S. Liu, K. Sun, X. Chen, B. Wang, K. Wu, X. Cao, W. C. Cheong, R. Shen, A. Han, Z. Chen, L. Zheng, J. Luo, Y. Lin, Y. Liu, D. Wang, Q. Peng, Q. Zhang, C. Chen, Y. Li, Angew. Chem. Int. Ed., 2018, 57, 8614-8618.

[86] L. Zhang, L. Han, H. Liu, X. Liu, J. Luo, Angew. Chem. Int. Ed., 2017, 56, 13694-13698.

[87] J. Yang, B. Chen, X. Liu, W. Liu, Z. Li, J. Dong, W. Chen, W. Yan, T. Yao, X. Duan, Y. Wu, Y. Li, Angew. Chem. Int. Ed., 2018, 57, 9495-9500.

[88] L. Ji, P. Yan, C. Zhu, C. Ma, W. Wu, C. Wei, Y. Shen, S. Chu, J. Wang, Y. Du, J. Chen, X. Yang, Q. Xu, Appl. Catal. B, 2019, 251, 87-93.

[89] D. Wang, Q. Li, C. Han, Z. Xing, X. Yang, Appl. Catal. B, 2019, 249, 91-97.

[90] S. Ye, F. Luo, Q. Zhang, P. Zhang, T. Xu, Q. Wang, D. He, L. Guo, Y. Zhang, C. He, X. Ouyang, M. Gu, J. Liu, X. Sun, Energy Environ. Sci,, 2019, 12, 1000-1007.

[91] J.-D. Yi, R. Xu, G.-L. Chai, T. Zhang, K. Zang, B. Nan, H. Lin, Y.-L. Liang, J. Lv, J. Luo, R. Si, Y.-B. Huang, R. Cao, J. Mater. Chem. A, 2019, 7, 1252-1259.

[92] Y. Wang, L. Chen, Z. Mao, L. Peng, R. Xiang, X. Tang, J. Deng, Z. Wei, Q. Liao, Sci. Bull., 2019, 64, 1095-1102.
[93] V. Ramalingam, P. Varadhan, H. C. Fu, H. Kim, D. Zhang, S. Chen, L. Song, D. Ma, Y. Wang, H. N. Alshareef, J. H. He, Adv. Mater., 2019, 31, e1903841.

[94] W. Chen, J. Pei, C. He, J. Wan, H. Ren, Y. Zhu, Y. Wang, J. Dong, S. Tian, W.-C. Cheong, S. Lu, L. Zheng, X. Zheng, W. Yan, Z. Zhuang, C. Chen, Q. Peng, D. Wang, Y. Li, Angew. Chem. Int. Ed., 2017, 56, 16086-16090.

[95] C. Cai, S. Han, Q. Wang, M. Gu, ACS Nano, 2019, 13, 8865-8871.

[96] Q. Song, J. Li, L. Wang, L. Pang, H. Liu, Inorg. Chem., 2019, 58, 10802-10811.

[97] L. Bai, C. S. Hsu, D. T. L. Alexander, H. M. Chen, X. Hu, J. Am. Chem. Soc., 2019, 141, 14190-14199.

[98] Y. Zheng, Y. Jiao, Y. Zhu, Q. Cai, A. Vasileff, L.H. Li, Y. Han, Y. Chen, S. Z. Qiao, J. Am. Chem. Soc., 2017, 139, 3336-3339.

[99] X. Han, X. Ling, D. Yu, D. Xie, L. Li, S. Peng, C. Zhong, N. Zhao, Y. Deng, W. Hu, Adv. Mater., 2019, 31, e1905622.

[100] L. Liu, H. Su, F. Tang, X. Zhao, Q. Liu, Nano Energy, 2018, 46, 110-116.

[101] J. Yan, L. Kong, Y. Ji, J. White, Y. Li, J. Zhang, P. An, S. Liu, S. T. Lee, T. Ma, Nat. Commun., 2019, 10, 2149.

[102] H. Fei, J. Dong, Y. Feng, C. S. Allen, C. Wan, B. Volosskiy, M. Li, Z. Zhao, Y. Wang, H. Sun, P. An, W. Chen, Z. Guo, C. Lee, D. Chen, I. Shakir, M. Liu, T. Hu, Y. Li, A. I. Kirkland, X. Duan, Y. Huang, Nat. Catal, 2018, 1, 63-72.

[103] Y. Yao, S. Hu, W. Chen, Z.-Q. Huang, W. Wei, T. Yao, R. Liu, K. Zang, X. Wang, G. Wu, W. Yuan, T. Yuan, B. Zhu, W. Liu, Z. Li, D. He, Z. Xue, Y. Wang, X. Zheng, J. Dong, C.-R. Chang, Y. Chen, X. Hong, J. Luo, S. Wei, W.-X. Li, P. Strasser, Y. Wu, Y. Li, Nat. Catal., 2019, 2, 304-313.

[104] P. Li, M. Wang, X. Duan, L. Zheng, X. Cheng, Y. Zhang, Y. Kuang, Y. Li, Q. Ma, Z. Feng, W. Liu, X. Sun, Nat. Commun., 2019, 10, 1711.

[105] C. Lin, Y. Zhao, H. Zhang, S. Xie, Y. F. Li, X. Li, Z. Jiang, Z. P. Liu, Chem. Sci., 2018, 9, 6803-6812.

[106] D. D. Babu, Y. Huang, G. Anandhababu, X. Wang, R. Si, M. Wu, Q. Li, Y. Wang, J. Yao, J. Mater. Chem. A, 2019, 7, 8376-8383.

[107] H. Zhang, Y. Liu, T. Chen, J. Zhang, J. Zhang, X. W. D. Lou, Adv. Mater., 2019, 31, e1904548.

[108] J. Wu, H. Zhou, Q. Li, M. Chen, J. Wan, N. Zhang, L. Xiong, S. Li, B. Y. Xia, G. Feng, M. Liu, L. Huang, Adv. Energy Mater., 2019, 9 , 1900149.

[109] I. S. Amiinu, X. Liu, Z. Pu, W. Li, Q. Li, J. Zhang, H. Tang, H. Zhang, S. $\mathrm{Mu}$, Adv. Funct. Mater., 2018, 28, 1704638.

[110] G. Sun, Z. J. Zhao, R. Mu, S. Zha, L. Li, S. Chen, K. Zang, J. Luo, Z. Li, S. C. Purdy, A. J. Kropf, J. T. Miller, L. Zeng, J. Gong, Nat. Commun., 2018, 9, 4454.

[111] M. D. Marcinkowski, J. Liu, C. J. Murphy, M. L. Liriano, N. A. Wasio, F. R. Lucci, M. Flytzani-Stephanopoulos, E. C. H. Sykes, ACS Catal., 2016, 7, 413-420.

[112] G. Giannakakis, M. Flytzani-Stephanopoulos, E. C. H. Sykes, Acc. Chem. Res., 2019, 52, 237-247.

[113] F. Xing, J. Jeon, T. Toyao, K.-I. Shimizu, S. Furukawa, Chem. Sci., 2019, 10, 8292-8298.

[114] T. Chao, X. Luo, W. Chen, B. Jiang, J. Ge, Y. Lin, G. Wu, X. Wang, Y. Hu, Z. Zhuang, Y. Wu, X. Hong, Y. Li, Angew. Chem. Int. Ed., 2017, $56,16047-16051$.

[115] X. P. Yin, H. J. Wang, S. F. Tang, X. L. Lu, M. Shu, R. Si, T. B. Lu, Angew. Chem. Int. Ed., 2018, 57, 9382-9386.

[116] E. Luo, H. Zhang, X. Wang, L. Gao, L. Gong, T. Zhao, Z. Jin, J. Ge, Z. Jiang, C. Liu, W. Xing, Angew. Chem. Int. Ed., 2019, 58, 12469-12475.

[117] J. Zhang, M. Zhang, Y. Zeng, J. Chen, L. Qiu, H. Zhou, C. Sun, Y. Yu, C. Zhu, Z. Zhu, Small, 2019, 15, e1900307. 
[118] C. Zhu, S. Fu, J. Song, Q. Shi, D. Su, M. H. Engelhard, X. Li, D. Xiao, D. Li, L. Estevez, D. Du, Y. Lin, Small, 2017, 13, 1603407.

[119] X. Lyu, G. Li, X. Chen, B. Shi, J. Liu, L. Zhuang, Y. Jia, Small Methods, 2019, 3, 1800450

[120] B. Zhang, J. Zhang, J. Shi, D. Tan, L. Liu, F. Zhang, C. Lu, Z. Su, X. Tan, X. Cheng, B. Han, L. Zheng, J. Zhang, Nat. Commun., 2019, 10, 2980

[121] Y. Wang, J. Li, Z. Wei, ChemElectroChem, 2018, 5, 1764-1774.

[122] P. Yin, T. Yao, Y. Wu, L. Zheng, Y. Lin, W. Liu, H. Ju, J. Zhu, X. Hong, Z. Deng, G. Zhou, S. Wei, Y. Li, Angew. Chem. Int. Ed., 2016, 55, 10800-10805

[123] S. Fu, C. Zhu, D. Su, J. Song, S. Yao, S. Feng, M. H. Engelhard, D. Du, Y. Lin, Small, 2018, 14, e1703118.

[124] J. Wang, G. Han, L. Wang, L. Du, G. Chen, Y. Gao, Y. Ma, C. Du, X. Cheng, P. Zuo, G. Yin, Small, 2018, 14, e1704282.

[125] Z. Yang, Y. Wang, M. Zhu, Z. Li, W. Chen, W. Wei, T. Yuan, Y. Qu, Q. Xu, C. Zhao, X. Wang, P. Li, Y. Li, Y. Wu, Y. Li, ACS Catal., 2019, 9, 2158-2163.

[126] K. Huang, R. Wang, H. Wu, H. Wang, X. He, H. Wei, S. Wang, R. Zhang, M. Lei, W. Guo, B. Ge, H. Wu, J. Mater. Chem. A, 2019, 7, 25779-25784.

[127] J. Li, S. Chen, N. Yang, M. Deng, S. Ibraheem, J. Deng, J. Li, L. Li, Z. Wei, Angew. Chem. Int. Ed., 2019, 58, 7035-7039.

[128] N. Jia, Q. Xu, F. Zhao, H.-X. Gao, J. Song, P. Chen, Z. An, X. Chen, Y. Chen, ACS Appl. Energy Mater., 2018, 1, 4982-4990.

[129] Z. Guo, Y. Xie, J. Xiao, Z.J. Zhao, Y. Wang, Z. Xu, Y. Zhang, L. Yin, H. Cao, J. Gong, J. Am. Chem. Soc., 2019, 141, 12005-12010.

[130] F. Li, G.-F. Han, H.-J. Noh, S.-J. Kim, Y. Lu, H.Y. Jeong, Z. Fu, J.-B. Baek, Energy Environ. Sci., 2018, 11, 2263-2269.

[131] Y. Wang, Y. Nie, W. Ding, S. G. Chen, K. Xiong, X. Q. Qi, Y. Zhang, J. Wang, Z. D. Wei, Chem. Commun., 2015, 51, 8942-8945.

[132] Y. Wang, W. Chen, Y. Chen, B. Wei, L. H. Chen, L. S. Peng, R. Xiang, J. Li, Z. C. Wang, Z. D. Wei, J. Mater. Chem. A, 2018, 6, 8405-8412.

[133] X. X. Wang, D. A. Cullen, Y. T. Pan, S. Hwang, M. Wang, Z. Feng, J. Wang, M. H. Engelhard, H. Zhang, Y. He, Y. Shao, D. Su, K. L. More, J. S. Spendelow, G. Wu, Adv. Mater, 2018, 30, 1706758.

[134] J. Han, X. Meng, L. Lu, J. Bian, Z. Li, C. Sun, Adv. Funct. Mater., 2019, 29, 1808872

[135] Y. Chen, S. Ji, Y. Wang, J. Dong, W. Chen, Z. Li, R. Shen, L. Zheng, Z. Zhuang, D. Wang, Y. Li, Angew. Chem. Int. Ed., 2017, 56, 6937-6941.

[136] X. Han, X. Ling, Y. Wang, T. Ma, C. Zhong, W. Hu, Y. Deng, Angew. Chem. Int. Ed., 2019, 58, 5359-5364.

[137] F. Xiao, G.-L. Xu, C.-J. Sun, M. Xu, W. Wen, Q. Wang, M. Gu, S. Zhu, Y. Li, Z. Wei, X. Pan, J. Wang, K. Amine, M. Shao, Nano Energy, 2019, 61, 60-68.

[138] W. Zhao, G. Wan, C. Peng, H. Sheng, J. Wen, H. Chen, ChemSusChem, 2018, 11, 3473-3479.

[139] D. Ji, L. Fan, L. Li, S. Peng, D. Yu, J. Song, S. Ramakrishna, S. Guo, Adv. Mater., 2019, 31, e1808267.

[140] B. Q. Li, C. X. Zhao, S. Chen, J. N. Liu, X. Chen, L. Song, Q. Zhang, Adv. Mater., 2019, 31, e1900592.

[141] P. Peng, L. Shi, F. Huo, S. Zhang, C. Mi, Y. Cheng, Z. Xiang, ACS Nano, 2019, 13, 878-884.

[142] G. Wan, X.-M. Lin, J. Wen, W. Zhao, L. Pan, J. Tian, T. Li, H. Chen, J. Shi, Chem. Mater., 2018, 30, 7494-7502.

[143] Z. K. Yang, C. Z. Yuan, A. W. Xu, Nanoscale, 2018, 10, 16145-16152.

[144] Y. Lin, P. Liu, E. Velasco, G. Yao, Z. Tian, L. Zhang, L. Chen, Adv. Mater., 2019, 31, e1808193.

[145] H. E. Kim, I. H. Lee, J. Cho, S. Shin, H. C. Ham, J. Y. Kim, H. Lee, ChemElectroChem, 2019, 6, 4757-4764.
[146] L. Yang, L. Shi, D. Wang, Y. Lv, D. Cao, Nano Energy, 2018, 50, 691-698.

[147] Y. Deng, B. Chi, X. Tian, Z. Cui, E. Liu, Q. Jia, W. Fan, G. Wang, D. Dang, M. Li, K. Zang, J. Luo, Y. Hu, S. Liao, X. Sun, S. Mukerjee, J. Mater. Chem. A, 2019, 7, 5020-5030.

[148] H. Fei, J. Dong, C. Wan, Z. Zhao, X. Xu, Z. Lin, Y. Wang, H. Liu, K. Zang, J. Luo, S. Zhao, W. Hu, W. Yan, I. Shakir, Y. Huang, X. Duan, Adv. Mater., 2018, 30, e1802146.

[149] H. L. Fei, J. C. Dong, M. J. Arellano-Jimenez, G. L. Ye, N. D. Kim, E. L. G. Samuel, Z. W. Peng, Z. Zhu, F. Qin, J. M. Bao, M. J. Yacaman, P. M. Ajayan, D. L. Chen, J. M. Tour, Nat. Commun., 2015, 6, 8668.

[150] H. J. Qiu, Y. Ito, W. Cong, Y. Tan, P. Liu, A. Hirata, T. Fujita, Z. Tang, M. Chen, Angew. Chem. Int. Ed., 2015, 54, 14031-14035.

[151] M. Tavakkoli, N. Holmberg, R. Kronberg, H. Jiang, J. Sainio, E. I. Kauppinen, T. Kallio, K. Laasonen, ACS Catal., 2017, 7, 3121-3130.

[152] Q. Li, W. Chen, H. Xiao, Y. Gong, Z. Li, L. Zheng, X. Zheng, W. Yan, W.C. Cheong, R. Shen, N. Fu, L. Gu, Z. Zhuang, C. Chen, D. Wang, Q. Peng, J. Li, Y. Li, Adv. Mater., 2018, 30, e1800588.

[153] A. Han, W. Chen, S. Zhang, M. Zhang, Y. Han, J. Zhang, S. Ji, L. Zheng, Y. Wang, L. Gu, C. Chen, Q. Peng, D. Wang, Y. Li, $A d v$. Mater., 2018, 30, e1706508.

[154] P. Song, M. Luo, X. Liu, W. Xing, W. Xu, Z. Jiang, L. Gu, Adv. Funct. Mater., 2017, 27, 1700802.

[155] G. Wan, P. Yu, H. Chen, J. Wen, C.-J. Sun, H. Zhou, N. Zhang, Q. Li, W. Zhao, B. Xie, T. Li, J. Shi, Small, 2018, 14, 1704319.

[156] H. Yang, L. Shang, Q. Zhang, R. Shi, G. I. N. Waterhouse, L. Gu, T. Zhang, Nat. Commun., 2019, 10, 4585 .

[157] S. Yang, J. Kim, Y. J. Tak, A. Soon, H. Lee, Angew. Chem. Int. Ed., 2016, 55, 2058-2062.

[158] Y. Guan, Y. Feng, J. Wan, X. Yang, L. Fang, X. Gu, R. Liu, Z. Huang, J. Li, J. Luo, C. Li, Y. Wang, Small, 2018, 14, e1800697.

[159] H.-F. Zhong, H. Yin, D.-X. Zhang, L.-Y. Gan, P. Wang, J. Phys. Chem. C, 2019, 123, 24220-24224.

[160] S. Yang, Y. J. Tak, J. Kim, A. Soon, H. Lee, ACS Catal., 2017, 7, 1301-1307.

[161] J. Zhang, J. Liu, L. Xi, Y. Yu, N. Chen, S. Sun, W. Wang, K. M. Lange, B. Zhang, J. Am. Chem. Soc., 2018, 140, 3876-3879.

[162] H. Zhang, L. Yu, T. Chen, W. Zhou, X. W. D. Lou, Adv. Funct. Mater., 2018, 28, 1807086 .

[163] Y. Li, L. Wang, A. Song, M. Xia, Z. Li, G. Shao, Electrochim. Acta, 2018, 268, 268-275.

[164] R. Luo, M. Luo, Z. Wang, P. Liu, S. Song, X. Wang, M. Chen, Nanoscale, 2019, 11, 7123-7128.

[165] D. Zhao, Z. Chen, W. Yang, S. Liu, X. Zhang, Y. Yu, W. C. Cheong, L. Zheng, F. Ren, G. Ying, X. Cao, D. Wang, Q. Peng, G. Wang, C. Chen, J. Am. Chem. Soc., 2019, 141, 4086-4093.

[166] Y. J. Gao, H. Zhuo, Y. Y. Cao, X. Sun, G. L. Zhuang, S. W. Deng, X. Zhong, Z. Z. Wei, J. G. Wang, Chin. J. Catal., 2019, 40, 152-159.

[167] W. Zhong, Y. Liu, M. Deng, Y. Zhang, C. Jia, O.V. Prezhdo, J. Yuan, J. Jiang, J. Mater. Chem. A, 2018, 6, 11105-11112.

[168] X. Li, P. Cui, W. Zhong, J. Li, X. Wang, Z. Wang, J. Jiang, Chem. Commun., 2016, 52, 13233-13236.

[169] C. Deng, R. He, W. Shen, M. Li, Phys. Chem. Chem. Phys., 2019, 21, 18589-18594.

[170] Z. Feng, R. Li, Y. Ma, Y. Li, D. Wei, Y. Tang, X. Dai, Phys. Chem. Chem. Phys., 2019, 21, 19651-19659.

[171] Y. Zhao, D. Ma, J. Zhang, Z. Lu, Y. Wang, Phys. Chem. Chem. Phys., 2019, 21, 20432-20441.

[172] Y. Zhou, G. Gao, J. Kang, W. Chu, L.-W. Wang, J. Mater. Chem. A, 2019, 7, 12050-12059.

[173] T. He, S.K. Matta, G. Will, A. Du, Small Methods, 2019, 3, 1800419 . 
[174] Y. Zhou, G. Gao, J. Kang, W. Chu, L.W. Wang, Nanoscale, 2019, 11, 18169-18175.

[175] J. Deng, H. Li, J. Xiao, Y. Tu, D. Deng, H. Yang, H. Tian, J. Li, P. Ren, X. Bao, Energy Environ. Sci., 2015, 8, 1594-1601.

[176] T. H. M. Lau, X. Lu, J. Kulhavy, S. Wu, L. Lu, T. S. Wu, R. Kato, J. S. Foord, Y. L. Soo, K. Suenaga, S. C. E. Tsang, Chem. Sci., 2018, 9, 4769-4776.

[177] K. Jiang, S. Back, A. J. Akey, C. Xia, Y. Hu, W. Liang, D. Schaak, E. Stavitski, J. K. Norskov, S. Siahrostami, H. Wang, Nat. Commun., 2019, 10, 3997.

[178] F. Li, Y. Bu, G. F. Han, H. J. Noh, S. J. Kim, I. Ahmad, Y. Lu, P. Zhang, H. Y. Jeong, Z. Fu, Q. Zhong, J. B. Baek, Nat. Commun., 2019, 10, 2623.

[179] Y. Ren, Y. Tang, L. Zhang, X. Liu, L. Li, S. Miao, D. Sheng Su, A. Wang, J. Li, T. Zhang, Nat. Commun., 2019, 10, 4500.

[180] L. DeRita, J. Resasco, S. Dai, A. Boubnov, H. V. Thang, A. S. Hoffman, I. Ro, G. W. Graham, S. R. Bare, G. Pacchioni, X. Pan, P. Christopher, Nat. Mater., 2019, 18, 746-751.

[181] Z. Chen, W. Gong, Z. Liu, S. Cong, Z. Zheng, Z. Wang, W. Zhang, J. Ma, H. Yu, G. Li, W. Lu, W. Ren, Z. Zhao, Nano Energy, 2019, 60, 394-403.

[182] Z. Jakub, J. Hulva, M. Meier, R. Bliem, F. Kraushofer, M. Setvin, M. Schmid, U. Diebold, C. Franchini, G. S. Parkinson, Angew. Chem. Int. Ed., 2019, 58, 13961-13968.

[183] Y. Pan, Y. Chen, K. Wu, Z. Chen, S. Liu, X. Cao, W. C. Cheong, T. Meng, J. Luo, L. Zheng, C. Liu, D. Wang, Q. Peng, J. Li, C. Chen, Nat. Commun., 2019, 10, 4290.

[184] W. Deng, H. Jiang, C. Chen, L. Yang, Y. Zhang, S. Peng, S. Wang, Y. Tan, M. Ma, Q. Xie, ACS Appl. Mater. Interfaces, 2016, 8, 13341-13347.

[185] C. Chen, G. Chen, X. Kong, Inorg. Chem., 2018, 57, 13020-13026.

[186] Y. Zhou, G. Gao, Y. Li, W. Chu, L. W. Wang, Phys. Chem. Chem. Phys., 2019, 21, 3024-3032.

[187] G. Gao, S. Bottle, A. Du, Catal. Sci. Technol., 2018, 8, 996-1001.

[188] H. Xu, D. Cheng, D. Cao, X.C. Zeng, Nat. Catal., 2018, 1, 339-348.

[189] H. C. Kwon, M. Kim, J. P. Grote, S. J. Cho, M. W. Chung, H. Kim, D. H. Won, A. R. Zeradjanin, K. J. J. Mayrhofer, M. Choi, H. Kim, C. H. Choi, J. Am. Chem. Soc., 2018, 140, 16198-16205.

[190] L. Zhang, R. Si, H. Liu, N. Chen, Q. Wang, K. Adair, Z. Wang, J. Chen, Z. Song, J. Li, M. N. Banis, R. Li, T. K. Sham, M. Gu, L. M. Liu, G. A. Botton, X. Sun, Nat. Commun., 2019, 10, 4936.

[191] W. Ren, X. Tan, W. Yang, C. Jia, S. Xu, K. Wang, S. C. Smith, C. Zhao, Angew. Chem. Int. Ed., 2019, 58, 6972-6976.
[192] M. A. Hunter, J. M. T. A. Fischer, Q. Yuan, M. Hankel, D. J. Searles, ACS Catal., 2019, 9, 7660-7667.

[193] D. Zhang, W. Chen, Z. Li, Y. Chen, L. Zheng, Y. Gong, Q. Li, R. Shen, Y. Han, W. C. Cheong, L. Gu, Y. Li, Chem. Commun., 2018, 54, 4274-4277.

[194] Y. Chen, Z. Li, Y. Zhu, D. Sun, X. Liu, L. Xu, Y. Tang, Adv. Mater, 2019, 31, e1806312.

[195] Y. Cheng, S. Zhao, B. Johannessen, J. P. Veder, M. Saunders, M. R. Rowles, M. Cheng, C. Liu, M. F. Chisholm, R. De Marco, H. M. Cheng, S. Z. Yang, S. P. Jiang, Adv. Mater., 2018, 30, e1706287.

[196] H. Jiang, Q. He, C. Wang, H. Liu, Y. Zhang, Y. Lin, X. Zheng, S. Chen, P. M. Ajayan, L. Song, Adv. Energy Mater., 2018, 8, 1800436.

[197] X. Qiu, X. Yan, H. Pang, J. Wang, D. Sun, S. Wei, L. Xu, Y. Tang, Adv. Sci., 2019, 6, 1801103.

[198] Z. Zhang, J. Sun, F. Wang, L. Dai, Angew. Chem. Int. Ed., 2018, 57, 9038-9043.

[199] S. Zhao, Y. Cheng, J.-P. Veder, B. Johannessen, M. Saunders, L. Zhang, C. Liu, M. F. Chisholm, R. De Marco, J. Liu, S.-Z. Yang, S. P. Jiang, ACS Appl. Energy Mater., 2018, 1, 5286-5297.

[200] X. Sun, S. Sun, S. Gu, Z. Liang, J. Zhang, Y. Yang, Z. Deng, P. Wei, J. Peng, Y. Xu, C. Fang, Q. Li, J. Han, Z. Jiang, Y. Huang, Nano Energy, 2019, 61, 245-250.

[201] K. Chi, Z. Chen, F. Xiao, W. Guo, W. Xi, J. Liu, H. Yan, Z. Zhang, J. Xiao, J. Liu, J. Luo, S. Wang, K. P. Loh, J. Mater. Chem. A, 2019, 7, 15575-15579.

[202] H. Zhang, W. Zhou, T. Chen, B. Y. Guan, Z. Li, X. W. Lou, Energy Environ. Sci., 2018, 11, 1980-1984.

[203] W. Xie, Y. Song, S. Li, J. Li, Y. Yang, W. Liu, M. Shao, M. Wei, Adv. Funct. Mater., 2019, 29, 1906477.

[204] T. Li, J. Liu, Y. Song, F. Wang, ACS Catal., 2018, 8, 8450-8458.

[205] J. Li, H. Liu, M. Wang, C. Lin, W. Yang, J. Meng, Y. Xu, K. A. Owusu, B. Jiang, C. Chen, D. Fan, L. Zhou, L. Mai, Chem. Commun., 2019, $55,334-337$.

[206] R. Shi, C. Tian, X. Zhu, C. Y. Peng, B. Mei, L. He, X. L. Du, Z. Jiang, Y. Chen, S. Dai, Chem. Sci., 2019, 10, 2585-2591.

[207] G. Han, Y. Zheng, X. Zhang, Z. Wang, Y. Gong, C. Du, M. N. Banis, Y.-M. Yiu, T.-K. Sham, L. Gu, Y. Sun, Y. Wang, J. Wang, Y. Gao, G. Yin, X. Sun, Nano Energy, 2019, 66, 104088.

[208] R. Lang, W. Xi, J. C. Liu, Y. T. Cui, T. Li, A. F. Lee, F. Chen, Y. Chen, L. Li, L. Li, J. Lin, S. Miao, X. Liu, A. Q. Wang, X. Wang, J. Luo, B. Qiao, J. Li, T. Zhang, Nat. Commun., 2019, 10, 234.

[209] L. Wang, M.-X. Chen, Q. Q. Yan, S. L. Xu, S.-Q. Chu, P. Chen, Y. Lin, H. W. Liang, Sci. Adv., 2019, 5, eaax6322.

\title{
电解水金属单原子催化剂的研究进展
}

\author{
王 尧 ${ }^{\mathrm{a}, \mathrm{b}}$, 黄 寻 ${ }^{\mathrm{b},}{ }^{*}$, 魏子栋 $^{\mathrm{b}}$ \\ ${ }^{a}$ 四川大学新能源与低碳技术研究院, 四川成都610065 \\ $\mathrm{b}^{\mathrm{b}}$ 重庆大学化学化工学院, 重庆市化工过程清洁能源与资源利用重点实验室, 重庆400044
}

\begin{abstract}
摘要: 氢能因其能量密度高、清洁无污染等特点, 作为替代化石燃料的能源载体得到了广泛的研究. 如何清洁高效地制备 氢气受到了大量研究者的关注. 当前, 以化石能源的热反应所得副产氢气是主要来源. 然而, 采用该类方法不仅不能摆脱 化石能源的使用以及温室气体的排放, 还会造成生产氢气的纯度不高, 碳氧化物杂质浓度过高的问题, 严重影响氢气的后 续使用. 采用可再生能源(太阳能、风能等)所产富余电, 进行电解水制氢, 产生的氢气不含碳氧化合物杂质, 纯度很高, 可以 真正实现碳的零排放, 被认为是未来氢气来源的重要方式. 目前, 电解水制氢在制氢市场的所占份额较小, 而造成这样局 面的主要因素是该过程中的高能耗问题. 为了降低能耗, 开发高效催化剂加速两个电极上的电解反应的动力学尤为重要. 近年, 金属单原子催化剂(SACs)因其独特的结构, 在很多研究中被用作电解水催化剂, 进而开发出大量高性能的金属单原 子电解水催化剂.
\end{abstract}


本文综述了近年SACs 在电解水催化方面的应用. 首先, 针对电解水反应本身, 总结了阴阳极两侧的电极反应机制以及 影响电极催化性能的关键吸附中间物种; 然后, 根据载体的不同, 即合金、碳以及其它化合物将SACs分为三类, 总结了相关 电解水催化研究现状, 并且针对不同类型SACs目前的发展情况, 提出了它们各自存在的问题. 其次, 进一步总结了影响 SACs电解水催化活性的因素, 提出了四种决定SACs催化性能的影响因子, 分别为金属原子的固有元素性质、配位环境、几 何结构和负载量; 同时讨论了这四类影响因素对SACs催化活性的影响机制, 总结了调控各类影响因素的方法, 为SACs的 设计提出了一些建议. 最后, 展望了SACs在电解水催化中的应用, 探讨了SACs在催化剂设计及催化机制研究方面的问题, 提出了SACs在电解水催化中的未来发展方向.

关键词: 单原子催化剂; 电解水; 固有元素性质; 配位环境; 几何结构

收稿日期: 2020-09-23. 接受日期: 2020-10-24. 上网日期: 2021-04-05.

*通讯联系人. 电话/传真: (023)65678931; 电子信箱: huangxun@cqu.edu.cn

基金来源：国家自然科学基金(21761162015,91834301, 21908148); 四川省科技项目; 中央高校基本科研业务费专项资金.

本文的电子版全文由Elsevier出版社在ScienceDirect上出版(http://www.sciencedirect.com/journal/chinese-journal-of-catalysis). 